\title{
A CCL24-dependent pathway augments eosinophilic airway inflammation in house dust mite-challenged $\mathrm{Cd}_{163^{-/}-}$mice
}

\author{
C Dai ${ }^{1,6}, X_{\text {Yao }}{ }^{1,6}$, EM Gordon ${ }^{1,6}$, A Barochia ${ }^{1}$, RA Cuento ${ }^{1}$, M Kaler ${ }^{1}$, KS Meyer $^{1}$, KJ Keeran ${ }^{2}$, \\ GZ Nugent ${ }^{2}, \mathrm{KR}$ Jeffries ${ }^{2}, \mathrm{X} \mathrm{Qu}{ }^{3}, \mathrm{Z}-\mathrm{X} \mathrm{Yu^{3 }}$, A Aponte ${ }^{4}, \mathrm{M} \mathrm{Gucek}^{4}, \mathrm{PK}$ Dagur $^{5}, \mathrm{JP} \mathrm{McCoy}^{5}$ and \\ SJ Levine ${ }^{1}$
}

CD163 is a macrophage scavenger receptor with anti-inflammatory and pro-inflammatory functions. Here, we report that alveolar macrophages (AMФs) from asthmatic subjects had reduced cell-surface expression of CD163, which suggested that CD163 might modulate the pathogenesis of asthma. Consistent with this, house dust mite (HDM)-challenged $\mathrm{Cd}_{163^{-/-}}$mice displayed increases in airway eosinophils and mucous cell metaplasia (MCM). The increased airway eosinophils and MCM in HDM-challenged $\mathrm{Cd} 163^{-1-}$ mice were mediated by augmented CCL24 production and could be reversed by administration of a neutralizing anti-CCL24 antibody. A proteomic analysis identified the calcium-dependent binding of CD163 to Dermatophagoides pteronyssinus peptidase 1 (Der p1). Der p1-challenged $\mathrm{Cd}_{163^{-/-}}$mice had the same phenotype as HDM-challenged $\mathrm{Cd} 163^{-I^{-}}$mice with increases in airway eosinophils, MCM and CCL24 production, while Der p1 induced CCL24 secretion by bone marrow-derived macrophages (BMMФs) from Cd163 ${ }^{-1-}$ mice, but not BMMФs from wild-type (WT) mice. Finally, airway eosinophils and bronchoalveolar lavage fluid CCL24 levels were increased in Der p1-challenged WT mice that received adoptively transferred AMФ's from Cd163 ${ }^{-/-}$mice. Thus, we have identified CD163 as a macrophage receptor that binds Der $\mathrm{p} 1$. Furthermore, we have shown that HDM-challenged $\mathrm{Cd}_{163^{-/}}$mice have increased eosinophilic airway inflammation and MCM that are mediated by a CCL24-dependent mechanism.

\section{INTRODUCTION}

Macrophages, which have key roles in microbial defense, neoplasia, autoimmunity, fibrosis, and wound healing, have increasingly been recognized to participate in the pathogenesis of asthma. ${ }^{1,2}$ For example, the M(interleukin (IL)-4) subset of alternatively activated macrophages (AAMs) produce C-C chemokines, such as CCL17 (TARC) and CCL24 (eotaxin-2), which mediate the recruitment of Th2 cells and eosinophils, respectively. ${ }^{3}$ CD163 is a scavenger receptor superfamily member that is exclusively expressed by cells of the monocyte/macrophage lineage. ${ }^{1,4-6}$ CD163 functions as a high-affinity receptor that mediates the calcium-dependent endocytosis of haptoglobin-hemoglobin $(\mathrm{Hp}-\mathrm{Hb})$ complexes, which clears free hemoglobin during intravascular hemolysis. ${ }^{7}$ CD163 also serves as a receptor for erythroblasts, TNFSF12, bacteria, and viruses. ${ }^{8-11}$

CD163 has been associated with both anti-inflammatory and pro-inflammatory functions of macrophages and monocytes. ${ }^{6}$ Expression of CD163 on human monocytes is increased by glucocortiocoids and IL-10, which suggested a role for CD163 in modulating macrophage function. ${ }^{6,12,13}$ For example, binding of $\mathrm{Hp}-\mathrm{Hb}$ complexes to human monocytes expressing CD163 increased IL-10 secretion that induced heme oxygenase-1 protein synthesis via an autocrine mechanism, thereby providing anti-inflammatory and anti-oxidant effects. ${ }^{6,14}$ In contrast, binding of bacteria by $\mathrm{CD} 163$ promoted TNF

\footnotetext{
${ }^{1}$ Laboratory of Asthma and Lung Inflammation, NHLBI, NIH, Bethesda, Maryland, USA. ${ }^{2}$ Animal Surgery and Resources Core Facility, NHLBI, NIH, Bethesda, Maryland, USA. ${ }^{3}$ Pathology Core Facility, NHLBI, NIH, Bethesda, Maryland, USA. ${ }^{4}$ Proteomics Core Facility, NHLBI, NIH, Bethesda, Maryland, USA and ${ }^{5}$ Flow Cytometry Core Facility, NHLBI, NIH, Bethesda, Maryland, USA. Correspondence: SJ Levine (levines@nhlbi.nih.gov)

${ }^{6}$ These co-first authors contributed equally to this work. 
production, while activation of CD163 by cross-linking with CD163-specific monoclonal antibodies induced the secretion of TNF, IL-1 $\beta$, IL- 6 , and nitric oxide. ${ }^{6,9,15}$ In addition, CD $163^{+}$ macrophages that are induced by iron overloading have an unrestrained pro-inflammatory M1 activation profile and mediated persistent inflammation, tissue breakdown, and impaired wound healing. ${ }^{16}$ However, it is not known whether macrophages that express CD163 regulate the pathogenesis of asthma. Here, we show that CD163 serves as a receptor that binds the house dust mite (HDM) peptidase, Dermatophagoides pteronyssinus peptidase 1 (Der p1), in a calcium-dependent manner and that HDM-challenged $\mathrm{Cd}_{163^{-/}}$mice have CCL24-dependent increases in eosinophilic airway inflammation and MCM.

\section{RESULTS}

\section{Alveolar macrophages from asthmatic patients have} reduced cell-surface expression of CD163

First, we assessed whether CD163 expression by alveolar macrophages (AMФs) is modified in human subjects with asthma (Table 1). Confocal microscopy demonstrated that human $\mathrm{CD}^{+}{ }^{+}$AMФs in bronchoalveolar lavage fluid (BALF) express CD163 (Figure 1a), while cell-surface expression of CD163 by BALF AMФs from asthmatic subjects was significantly decreased as compared with normal individuals (Figure 1b-d). This suggested that the reduced cell-surface expression of CD163 by BALF AMФs might modify the pathogenesis of asthma.

\section{Eosinophilic airway inflammation and $\mathrm{MCM}$ are augmented} in HDM-challenged $\mathrm{Cd}_{163^{-1}}$ mice

$C d 163^{-1-}$ mice were created from embryos that contained a targeted partial deletion of exon 1 of the Cd163 gene, which encodes the $5^{\prime}$ untranslated region and the initial 15 amino acids of the signal peptide, and a total deletion of exons 2 through 16. Exon 17, which encodes the $3^{\prime}$ UTR, was not located within the targeted deletion. $C d 163^{-/}$mice appeared normal with no obvious developmental abnormalities. PCR genotyping confirmed the deletion of intron 15-16 of the Cd163 gene in DNA isolated from $C d 163^{-/-}$mice, whereas mRNA corresponding to exons 6 and 7 of CD163 was not detected in the lungs of $\mathrm{Cd}_{163^{-/}}$mice by quantitative real-time PCR (qRT-PCR) (Figure 2a, b).

We then investigated whether airway inflammatory responses were modified in $C d 163^{-/-}$mice that had been sensitized and challenged by intranasal HDM administration (Figure 2c). There was a significant increase in total BALF inflammatory cells in HDM-challenged $\mathrm{Cd}_{163^{-/-}}$mice, which reflected a selective increase in eosinophils, whereas the number of macrophages, lymphocytes, and neutrophils were not modified (Figure 2d, e). Lung histology similarly revealed an increase in peri-bronchial inflammatory cell infiltrates in HDM-challenged $\mathrm{Cd}_{163^{-/}}$mice as compared with wild-type (WT) mice (Figure 2f). Serum levels of HDM-specific IgE were not significantly different in HDM-challenged $C d 163^{-/-}$mice as compared with WT mice, which showed that CD163 does not modify allergic

Table 1 Clinical characteristics of research subjects

\begin{tabular}{|c|c|c|c|}
\hline & Normal & Asthma & \\
\hline Age (years) & $38.3 \pm 5.4$ & $38.4 \pm 3.5$ & $P=\mathrm{NS}$ \\
\hline Gender (M:F) & $(2: 5)$ & $(2: 5)$ & \\
\hline Asthma severity (mild/moderate vs. severe) & $\mathrm{n} / \mathrm{a}$ & $5 / 2$ & \\
\hline Positive allergy skin test ${ }^{\mathrm{a}}$ & $2 / 7$ & $6 / 7$ & \\
\hline $\mathrm{FEV}_{1}$ (liters) & $3.51 \pm 0.20$ & $2.63 \pm 0.14$ & $P=0.002$ \\
\hline $\mathrm{FEV}_{1}$ (\% predicted) & $103 \pm 2.79$ & $82.7 \pm 4.67$ & $P=0.027$ \\
\hline Blood eosinophils $\left(k \mu l^{-1}\right)$ & $0.137 \pm 0.04$ & $0.223 \pm 0.05$ & $P=\mathrm{NS}$ \\
\hline Blood eosinophils (\%) & $2.34 \pm 0.62$ & $3.46 \pm 0.80$ & $P=\mathrm{NS}$ \\
\hline $\lg E\left(I \cup \mathrm{ml}^{-1}\right)$ & $59.17 \pm 25.38$ & $3651 \pm 3238$ & $P=\mathrm{NS}$ \\
\hline BALF macrophages ( $\times 10^{4}$ per ml) & $1,077 \pm 253$ & $808 \pm 247$ & $P=\mathrm{NS}$ \\
\hline BALF eosinophils ( $\times 10^{4}$ per ml) & 0 & $14 \pm 6$ & $P=\mathrm{NS}$ \\
\hline BALF lymphocytes ( $\times 10^{4}$ per ml) & $118 \pm 51$ & $168 \pm 89$ & $P=\mathrm{NS}$ \\
\hline BALF neutrophils $\left(\times 10^{4}\right.$ per $\left.\mathrm{ml}\right)$ & $65 \pm 17$ & $81 \pm 22$ & $P=\mathrm{NS}$ \\
\hline
\end{tabular}

Abbreviation: BALF, bronchoalveolar lavage fluid. Data are presented as mean \pm standard error of the mean. Statistical analyses were performed using a paired two-tailed $T$ test. A $P$-value of $\leq 0.5$ was considered as significant.

andicates positive skin test reactivity to at least one of six aeroallergens. 
a

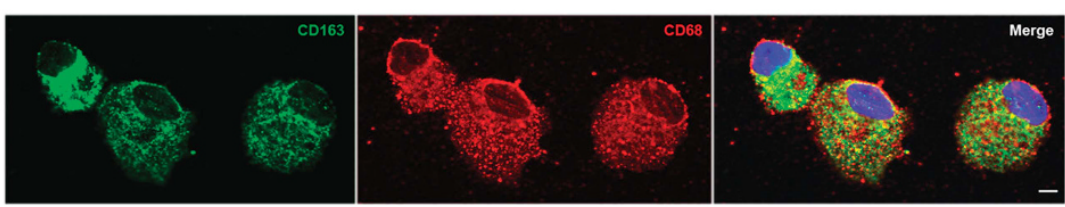

b
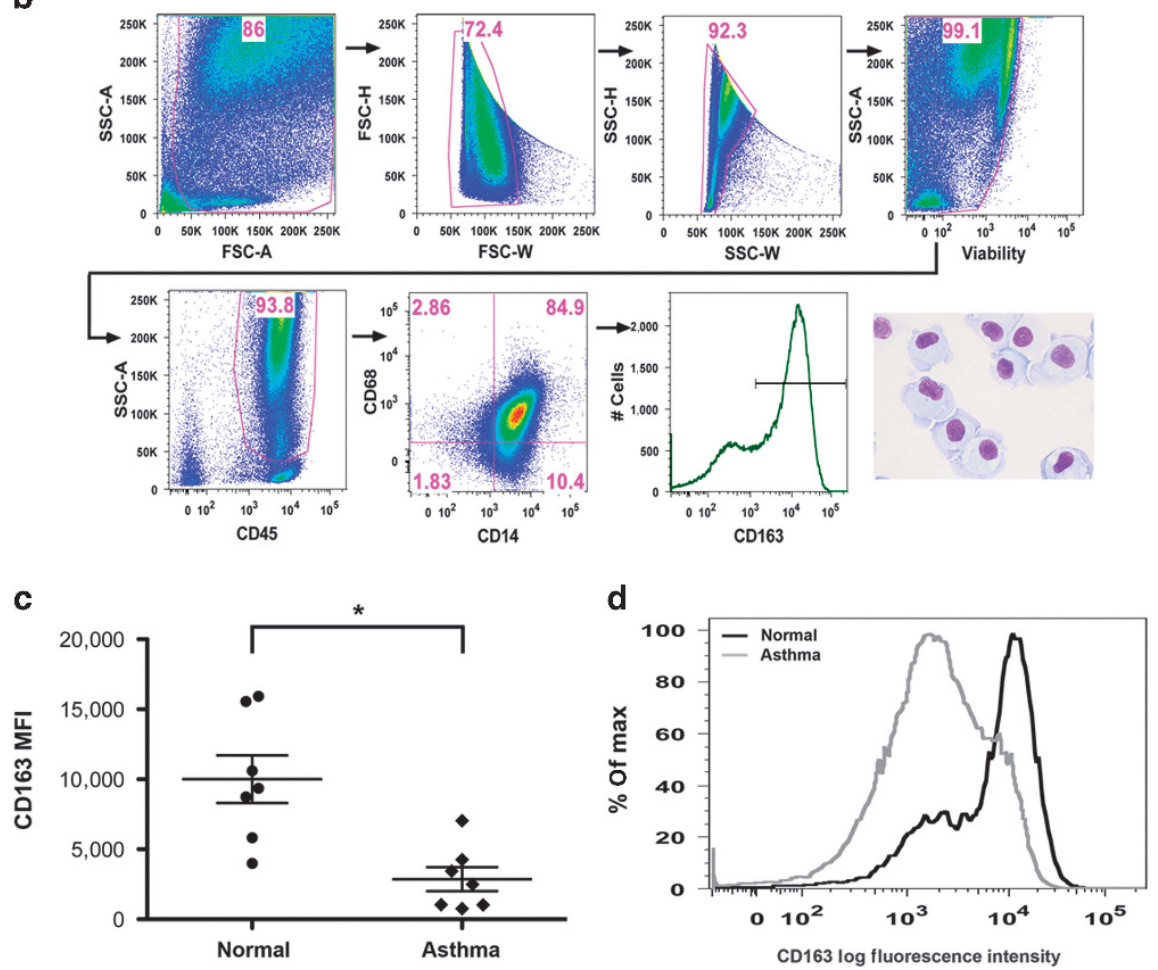

Figure 1 Alveolar macrophages (AMФs) from human asthmatics have reduced cell-surface expression of CD163. (a) Confocal immunofluorescence microscopy images of bronchoalveolar lavage fluid (BALF) cells from an asthmatic subject showing CD163 expression by CD68 ${ }^{+} \mathrm{AM}^{-} \mathrm{s}$. The scale bar indicates $5 \mu \mathrm{m}$. (b) Gating strategy for identification of human $\mathrm{CD}_{163^{+}}$alveolar macrophages in BALF. Cellular debris was excluded using a forward light scatter/side scatter plot and doublets were excluded using width parameter on forward light scatter (FSC) and side light scatter (SSC) properties. CD45 ${ }^{+}$ cells, that co-expressed CD14 and CD68, were identified as alveolar macrophages using side light scatter and CD45 bivariate plots from which lymphocytes had been excluded. A microscopic image of sorted $\mathrm{CD} 45^{+} / \mathrm{CD} 14^{+} / \mathrm{CD} 68^{+} / \mathrm{CD} 163^{+}$cells shows a cellular population possessing typical cellular characteristics of alveolar macrophages. (c) Mean fluorescence intensity (MFI) of cell-surface CD163 expression by $\mathrm{CD} 45^{+} / \mathrm{CD} 14^{+} / \mathrm{CD} 68^{+}$ AMФs in BALF from normal individuals and asthmatic subjects $\left(n=7,{ }^{*} P<0.008\right.$, paired $t$ test). (d) A representative histogram overlay comparing cellsurface CD163 expression by AMФs from a normal individual and an asthmatic subject.

sensitization to HDM (Figure $2 \mathrm{~g}$ ). Airway remodeling was significantly increased in HDM-challenged $C d 163^{-1-}$ mice based upon an increase in the percentage of airways with MCM (Figure 2f, $\mathbf{h}$ ) and by an increase in lung Muc5AC protein levels (Figure 2i, j). Finally, neither HDM-challenged $C d 163^{-1-}$ mice nor WT mice developed methacholine-induced increases in airway hyperreactivity in this model, which likely reflects the C57BL/6 genetic background. ${ }^{17}$ Collectively, these results demonstrate that $C d 163^{-1-}$ mice have a phenotype of increased eosinophilic airway inflammation and MCM in experimental murine HDM-induced asthma.

We next assessed whether the generation of AAMs was modified in HDM-challenged $C d 163^{-1-}$ mice. As shown in Figure 2k, BALF levels of the AAM product, Chi3L3/4, were increased in HDM-challenged $C d 163^{-1-}$ mice. ${ }^{3}$ We next used an intraperitoneal sensitization and intranasal challenge model of HDM-induced airway disease (Figure 3a), which again demonstrated that HDM-challenged $C d 163^{-1-}$ mice had an increase in BALF eosinophils as compared with WT mice (Figure 3b). Although the percentage of $\mathrm{CD} 206^{+}$AAMs was not significantly different between $\mathrm{HDM}$-challenged Cd163 ${ }^{-1-}$ mice and WT mice (Figure 3c), the mean fluorescence intensity of CD206 expression on BALF AAMs was significantly increased (Figure 3d).

\section{Eosinophilic airway inflammation is augmented in HDM-challenged $\mathrm{Cd}_{163^{-I-}}$ mice by a CCL24-dependent mechanism}

Experiments were next performed using the intranasal sensitization and challenge model (Figure 2c) to identify the mechanism by which the phenotype of HDM-induced eosinophilic airway inflammation and MCM are augmented in 
a

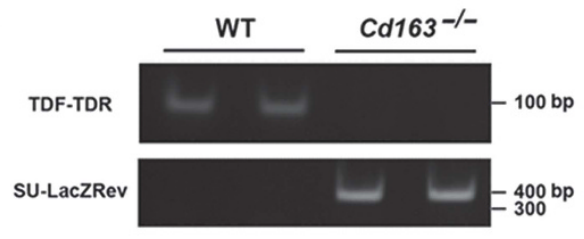

d

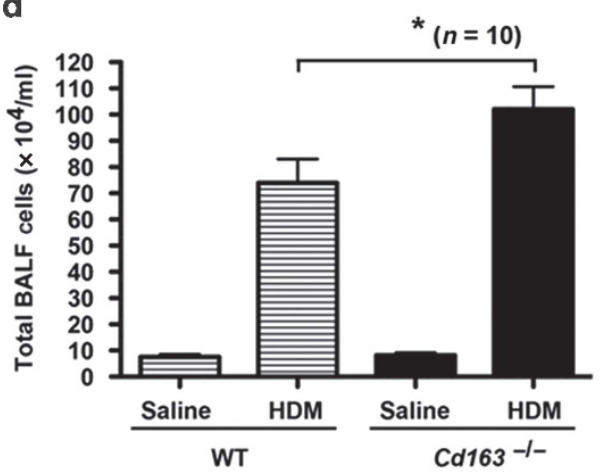

f

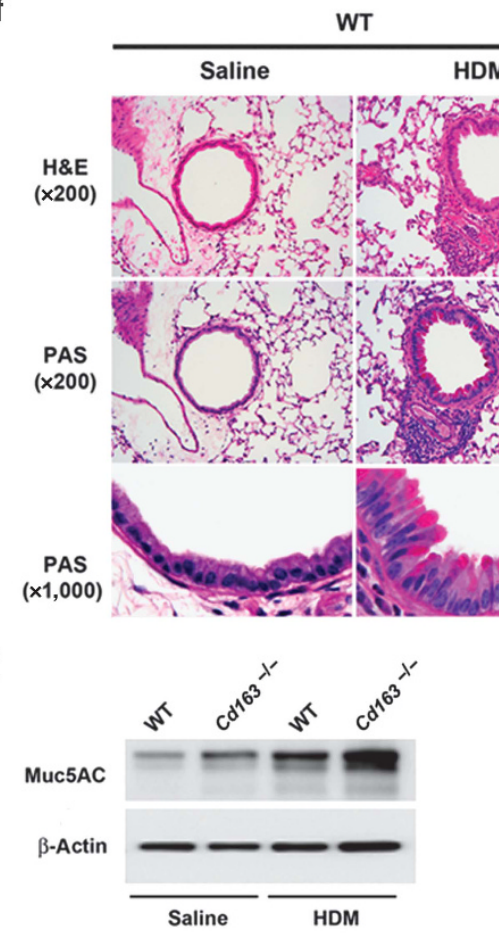

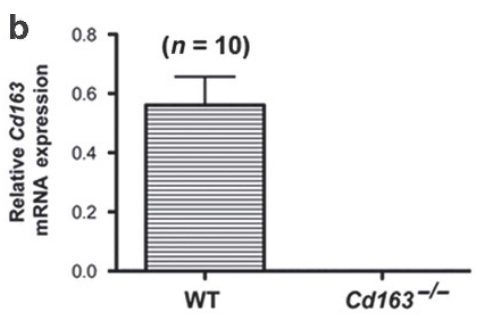

c

e

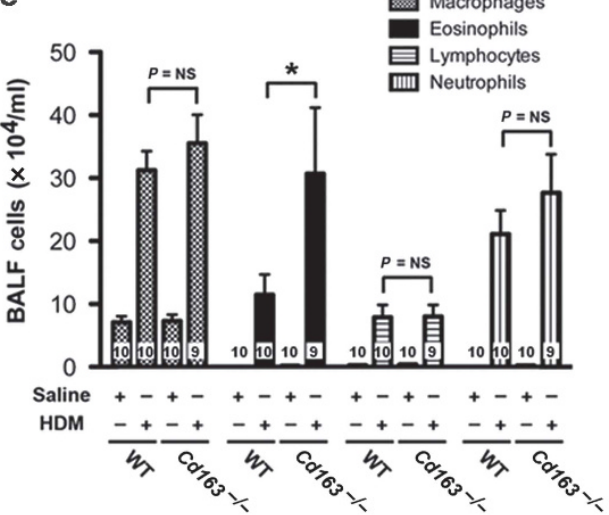

Cd163 ${ }^{-/-}$

Saline HDM

ax
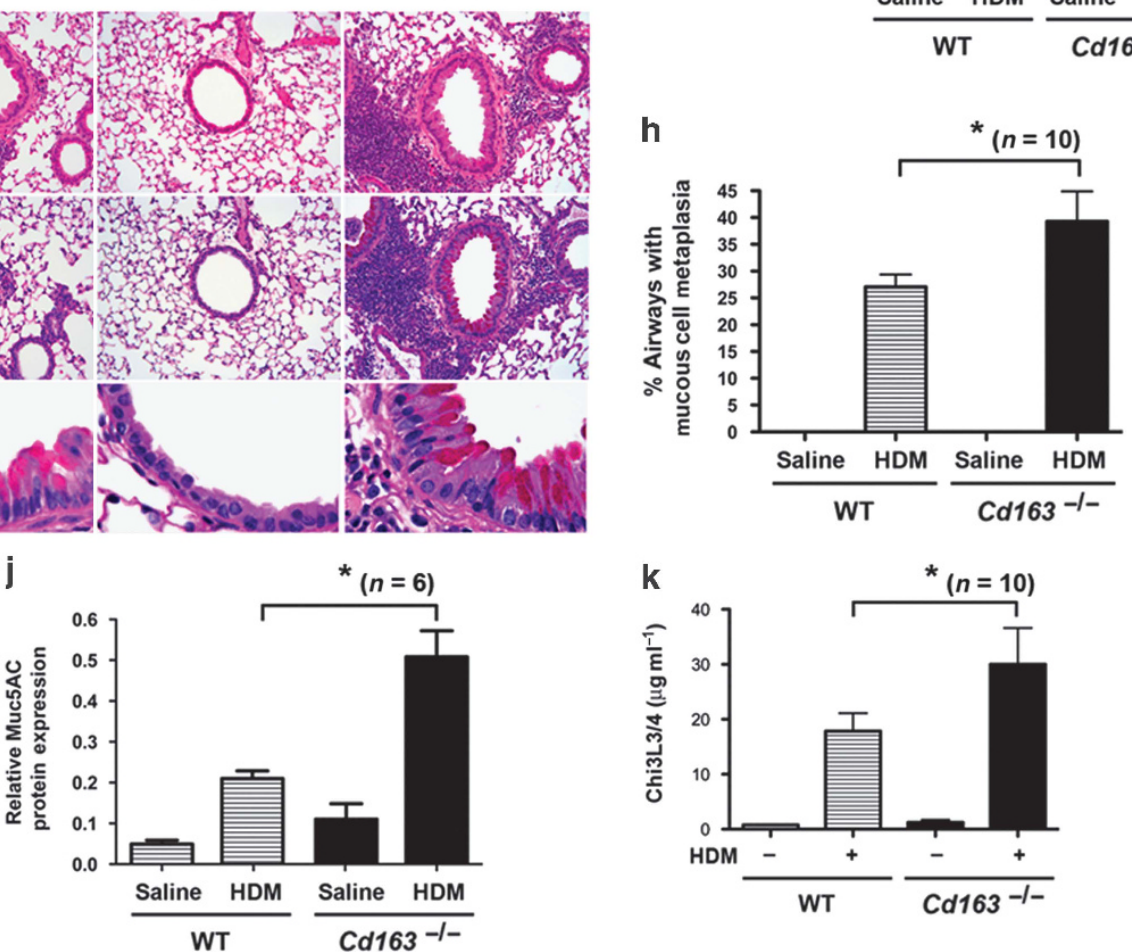

Figure 2 Eosinophilic airway inflammation and mucous cell metaplasia (MCM) are augmented in house dust mite (HDM)-challenged $C d 163^{-1-}$ mice.

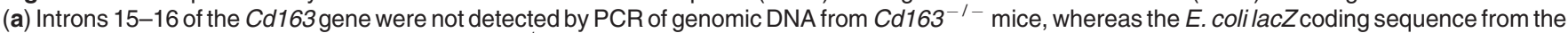
targeting vector could only be detected in $C d 163^{-1-}$ mice. Results from two mice are shown. (b) Cd163 mRNA was only detected by qRT-PCR in the lungs of wild-type (WT), but not $C d 163^{-1-}$ mice $\left(n=10\right.$ mice). (c) WT and $C d 163^{-1-}$ mice were sensitized and challenged by daily nasal administration of HDM $(25 \mu \mathrm{g})$ or saline, 5 days a week, for 5 weeks. End-point analysis was performed $24 \mathrm{~h}$ later. (d, e) Total bronchoalveolar lavage fluid (BALF) inflammatory cells (d) and inflammatory cell types $(\mathbf{e})\left(n=9-10\right.$ mice, $\left.{ }^{*} P<0.05\right)$. (f) Representative lung histology from WT and $C d 163^{-1-}$ mice that had been sensitized and challenged with saline or HDM were stained with hematoxylin and eosin $(\mathrm{H} \& \mathrm{E})(\times 200)$ or periodic acid Schiff $(\mathrm{PAS})(\times 200$ and $\times 1000)$. (g) Serum HDM-specific IgE ( $n=15$ mice). (h) Quantification of MCM $\left(n=10\right.$ mice, $\left.{ }^{*} P<0.01\right)$. (i) Western blots of lung proteins were reacted with antibodies against Muc5AC or $\beta$-actin. A representative blot from six replicate experiments is shown. (j) Relative Muc5AC expression as compared with $\beta$-actin was quantified by densitometry $\left(n=6,{ }^{*} P<0.001\right)$. (k) Chi3L3/4 protein in BALF $\left(n=10\right.$ mice, $\left.{ }^{*} P<0.05\right)$. (d, e, h, $\left.\mathbf{k}\right)$ Representative of two or three independent experiments. (g) Pooled data from two independent experiments. Numbers of mice that were included in each experimental condition are shown. 
a

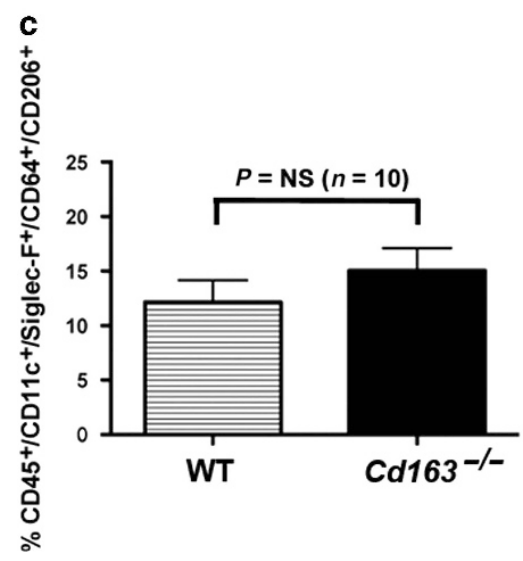

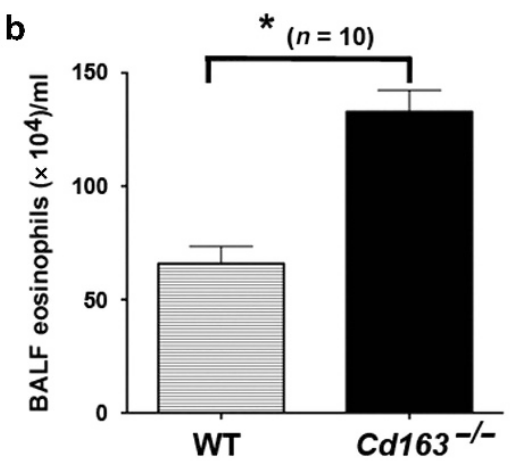

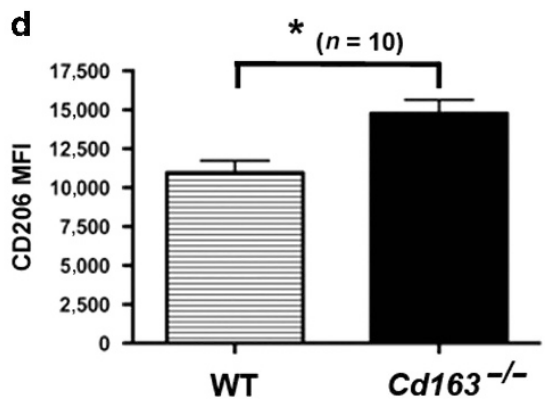

Figure 3 The percentage of M(IL-4) alternatively activated alveolar macrophages (AAMs) is not modified in house dust mite (HDM)-challenged $\mathrm{Cd}_{163^{-1-}}$ mice. (a) Wild-type (WT) and $\mathrm{Cd}_{163^{-1-}}$ mice were sensitized by intraperitoneal (i.p.) administration of $\mathrm{HDM}\left(50 \mu \mathrm{g} \mathrm{ml} \mathrm{m}^{-1}\right) \mathrm{emulsified} \mathrm{in} 2 \%$ aluminum hydroxide (ALUM) on days 1 and 4 , challenged with intranasal administration of HDM $(100 \mu \mathrm{g})$ on day 8 , and end points were analyzed on day 10. (b) Bronchoalveolar lavage fluid (BALF) eosinophils $\left(n=10\right.$ mice, ${ }^{*} P<0.0001$, Mann-Whitney test). (c) The percentage of CD45 ${ }^{+} / C D 11 c^{+} /$Siglec$\mathrm{F}^{+} / \mathrm{CD} 64^{+} / \mathrm{CD}_{206}{ }^{+}$BALF AAMs was quantified by flow cytometry $(n=10$ mice, $P=\mathrm{NS}$, Mann-Whitney test). (d) The mean fluorescence intensity (MFI) of CD206 expression by CD45 ${ }^{+} / \mathrm{CD}_{11 \mathrm{c}^{+}} /$Siglec $\mathrm{F}^{+} / \mathrm{CD} 64^{+} / \mathrm{CD}^{2} 06^{+}$BALF AAMs was quantified by flow cytometry $(n=10$ mice, $P=0.0029$, Mann-Whitney test). The gating strategy used to identify $\mathrm{CD} 45^{+} / \mathrm{CD} 11 \mathrm{c}^{+} / \mathrm{Siglec}^{-} \mathrm{F}^{+} / \mathrm{CD} 64^{+} \mathrm{BALF}$ alveolar macrophages is presented in Supplementary Figure 1 online. Data are pooled from two independent experiments.

Cd163-1- mice. There was no difference between HDMchallenged WT and $C d 163^{-1-}$ mice in the quantity of Th2 (IL5 and IL-13), Th1 (interferon (IFN)- $\gamma$ ), or Th17 (IL-17A) cytokines present in lung homogenates (Figure 4a) or secreted by mediastinal lymph node (MLN) cell cultures following ex vivo re-stimulation with HDM (Figure $4 \mathbf{b}$ ). We next assessed whether CD163 modulated the production of chemokines, such as CCL11 (eotaxin-1) and CCL24 (eotaxin-2), that mediate the chemotaxis of eosinophils to the lung. ${ }^{18}$ As shown in Figure 4c, CCL24 protein levels were significantly increased in BALF and lungs of HDM-challenged $C d 163^{-1-}$ mice, whereas the levels of CCL11, CCL17, and CCL22 were either unchanged or decreased. These experiments suggest that the increase in eosinophilic lung inflammation in HDM-challenged $C d 163^{-1-}$ mice might be mediated by an increase in CCL24 production.

To address whether the increases in eosinophilic lung inflammation in HDM-challenged $C d 163^{-/-}$mice were mediated via a CCL24-dependent mechanism, mice were treated with a neutralizing anti-CCL24 antibody (Figure 5a). HDM-challenged $C d 163^{-/-}$mice that received site-directed delivery of the neutralizing anti-CCL24 antibody to the lung had significant reductions in the number of BALF eosinophils, MCM, and peri-bronchial inflammatory cell infiltrates as compared with $C d 163^{-1-}$ mice that received a control antibody (Figure 5b-d). Since CD163 is expressed by AMФs in the lung, we assessed whether CD163 attenuates HDM-mediated CCL24 release from AMФs. AMФs were isolated from HDMchallenged WT and $C d 163^{-1-}$ mice and re-stimulated with HDM for $24 \mathrm{~h}$. As shown in Figure 5e, ex vivo re-stimulation with HDM significantly increased the amount of CCL24 secreted by Cd163 ${ }^{-1-}$ AMФs as compared with WT AMФs.

We next utilized two adoptive transfer models to assess whether dendritic cells (DCs) could possibly represent the relevant cell type mediating the increases in BALF eosinophils in HDM-challenged $C d 163^{-1-}$ mice. As shown in Figure 6a-d, there was no difference in BALF total cells, eosinophils, or CCL24 levels in HDM-challenged WT recipient mice that had received the adoptive transfer of HDM-pulsed bone marrow-derived DCs (BMDCs) from donor WT or $C d 163^{-1-}$ mice. Similarly, there was no difference in BALF total cells, eosinophils, or CCL24 levels in HDM-challenged $\mathrm{WT}$ recipient mice that received the adoptive transfer of CD11c ${ }^{+}$DCs isolated from MLNs from WT or Cd163 ${ }^{-1-}$ donor mice that had been pulsed in vivo with HDM (Figure 6e-h). Thus, CD163 expression by DCs did not appear to mediate the increases in BALF eosinophils or CCL24 levels in HDM-challenged $C d 163^{-/-}$mice.

We also assessed whether the increased eosinophilic airway inflammation and MCM in the HDM-challenged $C d 163^{-1-}$ mice might be mediated at the level of effector $\mathrm{CD} 4{ }^{+} \mathrm{T}$ cells. To address this question, splenic $\mathrm{CD} 4^{+} \mathrm{T}$ cells from donor $\mathrm{WT}$ 
a

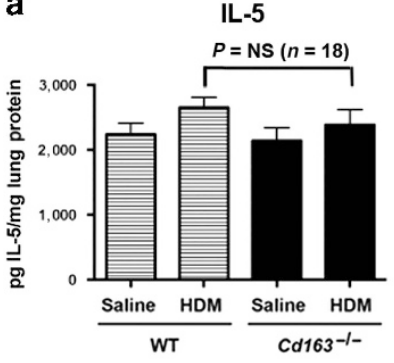

b

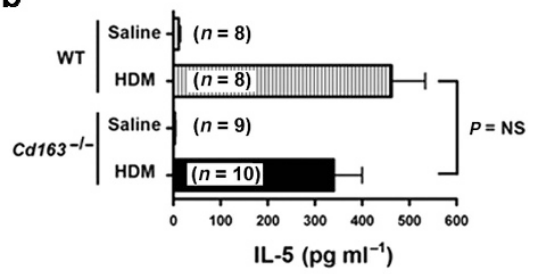

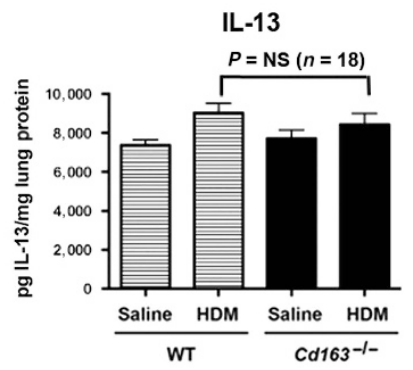
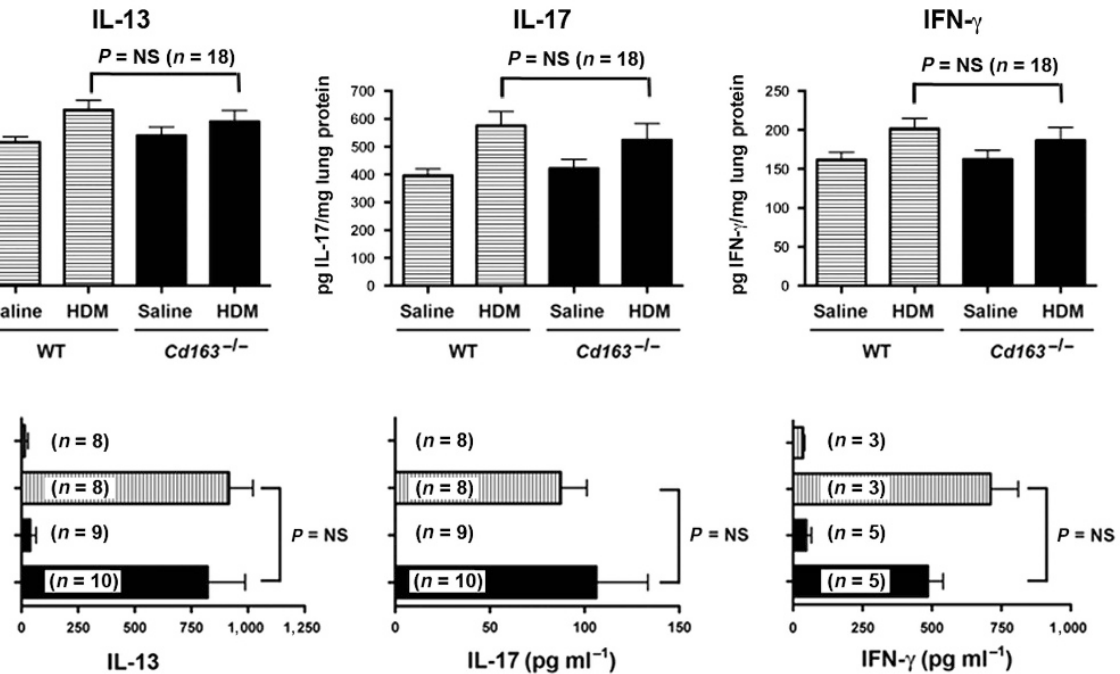

C
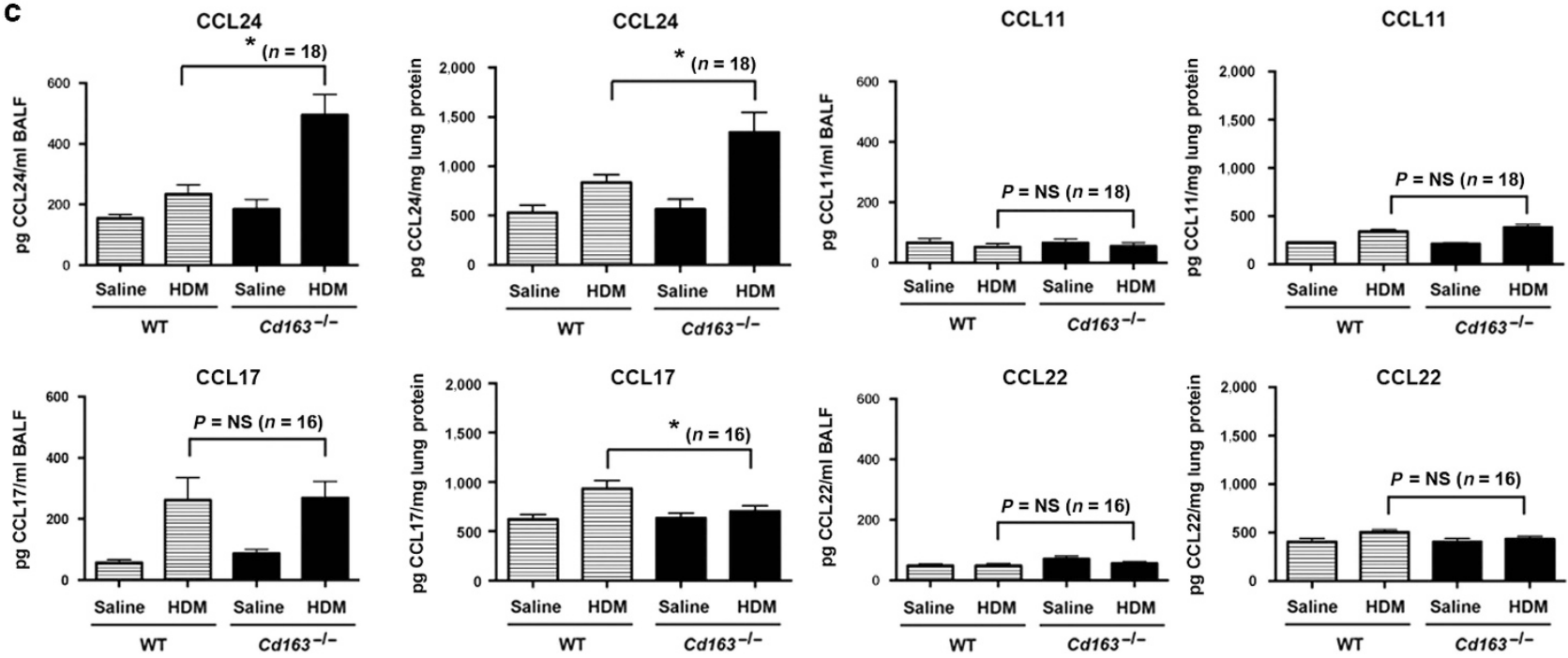

Figure 4 CCL24 is increased in the lungs of house dust mite (HDM)-challenged $C d 163^{-1-}$ mice. Wild-type (WT) and Cd163 ${ }^{-1-}$ mice were sensitized and challenged by daily nasal administration of $\operatorname{HDM}(25 \mu \mathrm{g})$ or saline, 5 days a week, for 5 weeks and end points were analyzed $24 \mathrm{~h} \mathrm{later}$. (a) Cytokines in lung homogenates from HDM-challenged WT and $C d 163^{-1-}$ mice $(n=18$ mice). (b) Ex vivo cultures of mediastinal lymph node cells from HDMchallenged WT and $C d 163^{-1-}$ mice were re-stimulated with HDM $\left(100 \mu \mathrm{g} \mathrm{ml}^{-1}\right)$ or saline (as a control) and cytokine secretion was quantified $(n=3-10$ mice). (c) Chemokines in bronchoalveolar lavage fluid (BALF) and lung homogenates $\left(n=16-18\right.$ mice, $\left.{ }^{*} P<0.01\right)$. Data in (a and $\left.\mathbf{c}\right)$ are pooled from two independent experiments, while (b) is representative of two independent experiments that showed similar results. Numbers of mice that were included in each experimental condition are shown.

mice that had been sensitized to HDM by intraperitoneal injection were isolated and adoptively transferred to recipient WT and $C d 163^{-1-}$ mice (Figure 7a). As shown in Figure 7b, c, $C d 163^{-1-}$ recipients of WT effector $\mathrm{CD}^{+}$splenic $\mathrm{T}$ cells showed increases in BAL eosinophils and MCM in response to multiple HDM challenges as compared with WT recipients of $\mathrm{CD}^{+}{ }^{+} \mathrm{T}$ cells from WT mice. Therefore, the adoptive transfer of WT effector $\mathrm{CD}^{+}{ }^{+} \mathrm{T}$ cells did not modify the phenotype of increased eosinophilic airway inflammation and MCM in HDM-challenged $C d 163^{-/-}$mice.

\section{Calcium-dependent binding of Der p1 to CD163}

Next, we hypothesized that CD163 might serve as a receptor for an HDM protein, which would be consistent with its function as a scavenger receptor. ${ }^{6-9,11}$ Immobilized recombinant human CD163 (rhCD163) was used to pull-down interacting proteins in $D$. pteronyssinus extracts, which were resolved by onedimensional gel electrophoresis, visualized by silver staining, and identified by mass spectroscopy. As shown in Figure 8a, eight distinct bands were pulled down when $D$. pteronyssinus extract proteins were incubated with immobilized rhCD163. In two independent experiments, band \#6 contained a 17 aminoacid peptide (GIEYIQHNGVVQESYYR) that corresponded to amino acids $177-193$ of Der p1, a cysteine protease that is one of the major allergens in $D$. pteronyssinus. ${ }^{19}$ Der $\mathrm{p} 1$ was the only $D$. pteronyssinus protein that was identified. Furthermore, band \#6 displayed a molecular weight of approximately $23 \mathrm{kDa}$, which is consistent with the molecular weight of Der p1. 
a
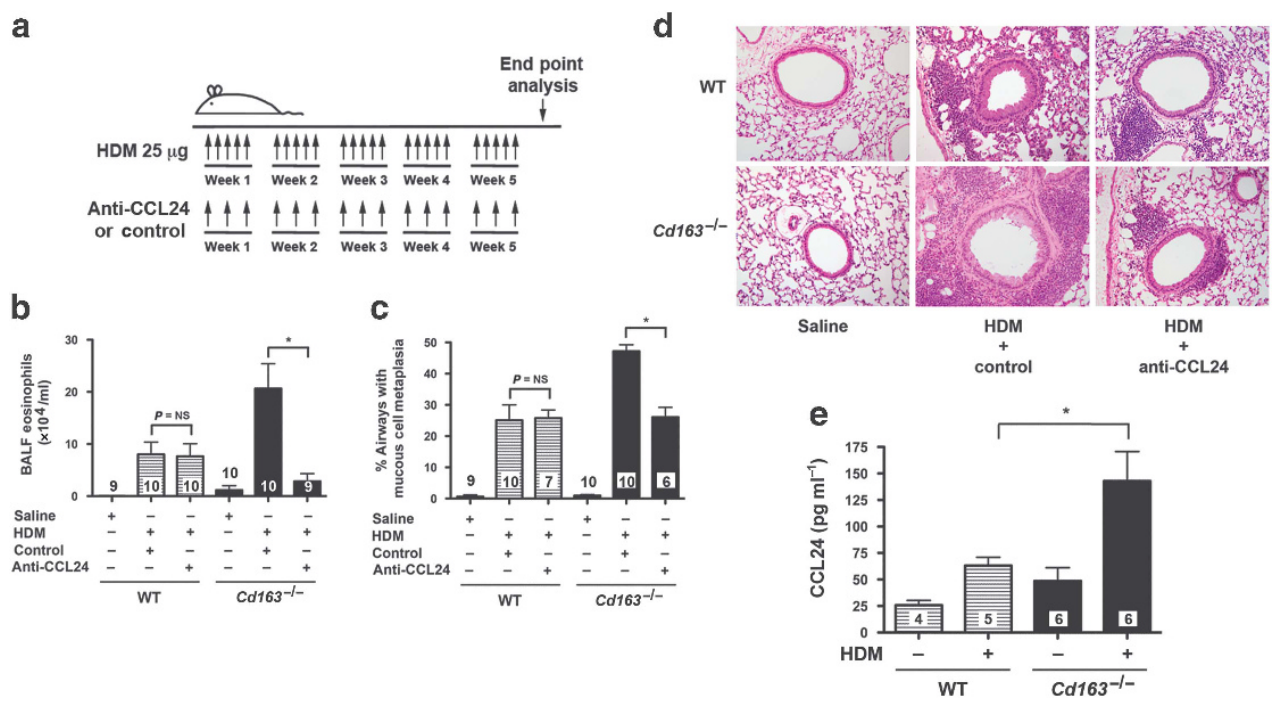

Figure 5 CCL24 neutralization prevents augmented eosinophilic airway inflammation and mucous cell metaplasia (MCM) in house dust mite (HDM)challenged $\mathrm{Cd}_{163^{-1}-}$ mice. (a) Wild-type (WT) and $C d 163^{-1-}$ mice were sensitized and challenged by daily intranasal administration of HDM (25 $\mu \mathrm{g}$ ) or saline, 5 days a week, for 5 weeks. Mice received concurrent nasal administration of a neutralizing anti-CCL24 antibody or control immunoglobulin, 3 days a week for 5 weeks. End-point analysis was performed $24 \mathrm{~h}$ later. (b) Bronchoalveolar lavage fluid (BALF) eosinophils $\left(n=9-10\right.$ mice, ${ }^{*} P<0.0001$, $\mathrm{HDM}+$ control antibody vs. HDM + anti-CCL24 neutralizing antibody). (c) Quantification of MCM $\left(n=6-10\right.$ mice, ${ }^{*} P<0.0001, \mathrm{HDM}+\mathrm{control}$ antibody vs. HDM + anti-CCL24 neutralizing antibody). (d) Representative histologic lung sections stained with hematoxylin and eosin ( $\times 200)$. (e) AMФs were isolated from HDM-challenged WT and $\mathrm{Cd}_{163^{-}}$mice, cultured ex vivo with or without $\mathrm{HDM}\left(500 \mu \mathrm{g} \mathrm{ml}{ }^{-1}\right)$ and CCL24 secretion was quantified $\left(n=3-5\right.$ mice, ${ }^{*} P<0.01, C d 163^{-1-}+$ HDM vs. WT + HDM). Panels (b and $\mathbf{c}$ ) represent pooled data from two independent experiments, while panel (e) is representative data from one of two independent experiments. Numbers of mice that were included in each experimental condition are shown.

Additional experiments were performed to confirm and characterize the ability of CD163 to function as a Der p1binding protein. First, immobilized rhCD163 protein pulled down purified Der p1 protein (Figure 8b), while immobilized Der p1 pulled down rhCD163 (Figure 8c). Nominal binding occurred when the resin that had been blocked with ovalbumin (OVA) alone was used for the pull-down experiments. Second, Der p1 protein that had been immobilized to plastic bound rhCD163 in a concentration-dependent and calcium-dependent manner (Figure 8d), which was significantly attenuated by EGTA (Figure 8e). Third, immobilized Der p1 protein pulled down CD163 from a lysate of human monocyte proteins (Figure 8f) that had the same molecular weight as native CD163. Furthermore, the amount of CD163 in human monocyte lysates that was pulled down by immobilized Der 1 protein was increased by the addition of supplemental calcium and attenuated by EGTA (Figure 8g). This is consistent with the requirement of calcium for binding of hemoglobin-haptoglobin complexes to CD163. ${ }^{20}$ Collectively, these results demonstrate that CD163 binds Der p1 in a calcium-dependent manner.

Experiments were next conducted to assess whether Der p1 modifies CCL24 secretion by bone marrow-derived macrophages (BMMФs) from WT and $C d 163^{-1-}$ mice. ${ }^{21}$ As shown in Figure 8h, purified Der p1 induced CCL24 secretion from ВMMФs from $C d 163^{-1-}$ mice, but not those from WT mice. This finding shows that CD163-deficient ВМMФs secrete increased amounts of CCL24 in response to Der p1 stimulation as compared with WT BMMФs.

\section{AMФs from $C d 163^{-/-}$mice enhance Der p1-induced eosinophilic airway inflammation and $\mathrm{MCM}$}

Having shown that CD163 binds Der p1 to suppress CCL24 secretion, we next assessed whether $C d 163^{-1-}$ mice that were sensitized and challenged with Der p1 had the same phenotype of increased airway eosinophils, MCM, and BALF CCL24 levels as HDM-challenged $\mathrm{Cd}_{163^{-1-}}$ mice (Figure 9a). As shown in Figure 9b, c, Der p1 induced significant increases in total BALF cell numbers, which primarily reflected an increase in eosinophils in $C d 163^{-1-}$ mice as compared with WT mice. Similarly, lung histology showed increased peri-bronchial inflammatory infiltrates and MCM in Der p1-challenged $\mathrm{Cd}_{163^{-/-}}$mice (Figure 9c, d). BALF levels of CCL24 were also significantly increased in Der p1-challenged Cd163 ${ }^{-1-}$ mice (Figure 9e). In contrast, there was no difference in the amount of IL-5 and IL-13 produced by MLN cells from $C d 163^{-1-}$ and WT mice when re-stimulated with HDM (Figure 9f). Collectively, these results demonstrate that sensitization and challenge with Der p1 induce a similar phenotype of increased eosinophilic airway inflammation, MCM and CCL24 production in Cd163 ${ }^{-1-}$ mice as was seen with the HDM-challenge model.

Finally, adoptive transfer experiments were performed to assess whether CD163 expression by AMФs modulates Der p1-induced CCL24 production and eosinophilic airway inflammation (Figure 10a). BALF $\mathrm{CD} 45^{+} / \mathrm{CD} 11 \mathrm{c}^{+} /$Siglec$\mathrm{F}^{+} / \mathrm{CD} 64^{+} \mathrm{AM}$ s from naïve donor $\mathrm{WT}$ and $\mathrm{Cd} 163^{-1-}$ mice (Figure 10b) were adoptively transferred to recipient WT mice that had been sensitized with Der p1 or saline, as a control. 
a

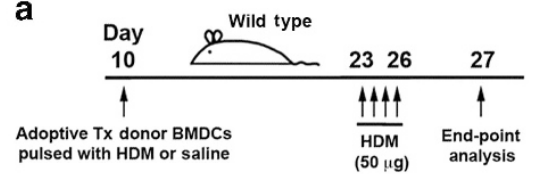

b

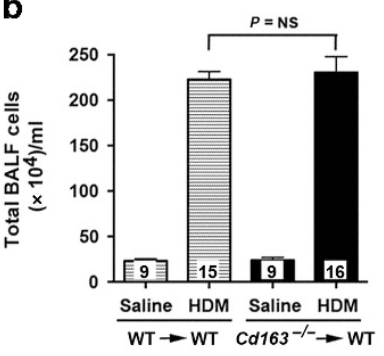

c

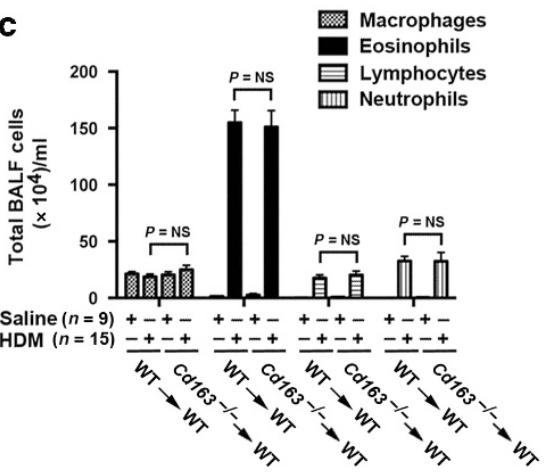

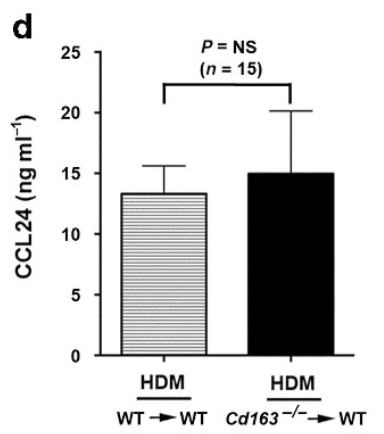

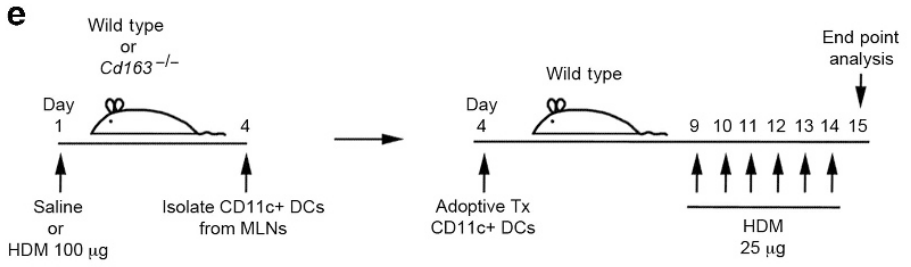

f

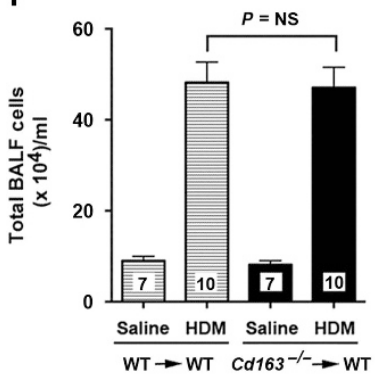

g

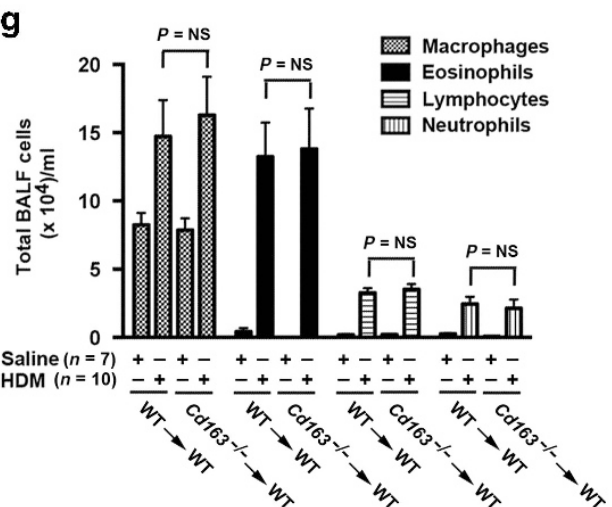

h

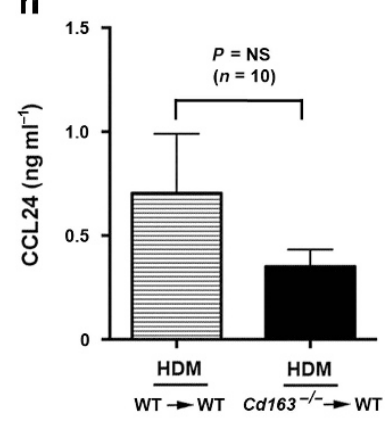

Figure 6 The adoptive transfer of house dust mite (HDM)-pulsed dendritic cells (DCs) from Cd163-1- mice to recipient wild-type (WT) mice does not induce increases in eosinophilic airway inflammation or bronchoalveolar lavage fluid (BALF) CCL24 levels. (a) Bone marrow-derived dendritic cells (BMDCs) from WT and $\mathrm{Cd}_{163^{-1-}}$ mice that had been pulsed with HDM or saline, as a control, were adoptively transferred to WT recipient mice on day 10. All mice received nasal HDM challenges on days 23 through 26 and end points were analyzed on day 27. (b, c) Total BALF inflammatory cells (b) and inflammatory cell types (c) $\left(n=9-16\right.$ mice). (d) CCL24 in BALF ( $n=15$ mice, $P=$ NS, Mann-Whitney test). (e) CD11c ${ }^{+}$DCs isolated from mediastinal lymph nodes (MLNs) of WT and Cd163 ${ }^{-1-}$ mice that had been pulsed in vivo by intranasal administration of HDM (100 $\left.\mu \mathrm{g}\right)$ or saline, as a control, were adoptively transferred to WT recipient mice. All mice received nasal HDM challenges on days 9 through 14 and end points were analyzed on day 15 . $(\mathbf{f}, \mathbf{g})$ Total BALF inflammatory cells (f) and inflammatory cell types (g) $(n=7-10$ mice). (h) CCL24 in BALF ( $n=10$ mice, $P=$ NS, Mann-Whitney test). Panels ( $\mathbf{b}-\mathbf{d}$ and $\mathbf{f}-\mathbf{h}$ ) represent pooled data from two independent experiments. Numbers of mice that were included in each experimental condition are shown. The same numbers of mice are shown for $(\mathbf{b}, \mathbf{c})$ and $(\mathbf{f}, \mathbf{g})$.

As shown in Figure 10c-d, both BALF eosinophils and CCL24 levels were significantly increased in Der p1-challenged recipient WT mice that received the adoptive transfer of Cd163-/- AMФs as compared with Der p1-challenged recipient WT mice that received the adoptive transfer of WT АMФs. Collectively, this provides additional evidence supporting the conclusion that Der p1-induced eosinophilic airway inflammation and BALF CCL24 levels are augmented by $C d 163^{-1-}$ AMФs.

\section{DISCUSSION}

Eosinophils are key effector inflammatory cells in allergenmediated asthma that are recruited to the airways by cooperative effects between the Th2 cytokine, IL-5, and C-C chemokines. ${ }^{22-24}$ IL-5 is a hematopoietic growth factor for eosinophils that both mobilizes eosinophil progenitor cells from the bone marrow to the circulation and increases CCR3 expression. ${ }^{25,26}$ Eotaxins are $\mathrm{C}-\mathrm{C}$ chemokines that mediate the chemotaxis of circulating eosinophils to the lung via binding to 

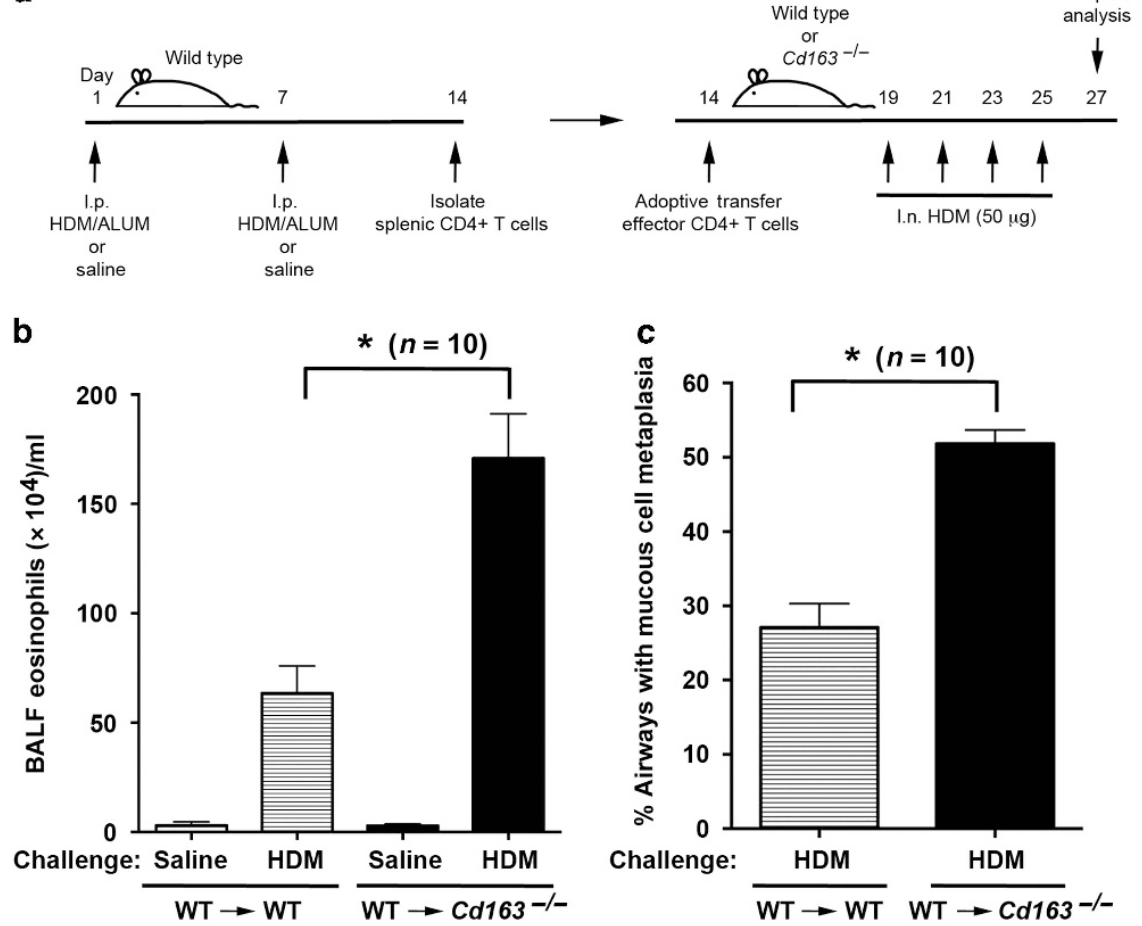

Figure 7 The adoptive transfer of WT effector $\mathrm{CD} 4^{+} \mathrm{T}$ cells does not modify the phenotype of increased eosinophilic airway inflammation and mucous cell metaplasia (MCM) in house dust mite (HDM)-challenged $\mathrm{Cd}_{163^{-1}}$ mice. (a) Effector splenic CD4 ${ }^{+} \mathrm{T}$ cells were isolated from wild-type (WT) mice that had been sensitized by intraperitoneal (i.p.) administration of saline or HDM $\left(100 \mu \mathrm{g} \mathrm{ml}^{-1}\right)$ emulsified in $2 \%$ aluminum hydroxide (ALUM) on days 1 and 7. On day $14,2 \times 10^{6} \mathrm{CD} 4^{+}$T cells were purified from the spleens of sensitized mice and adoptively transferred via intraperitoneal administration to recipient WT and $C d 163^{-\prime-}$ mice. All recipient mice received intranasal HDM challenges $(50 \mu \mathrm{g})$ on days $19,21,23$, and 25 and end points were analyzed on day 27. (b) Bronchoalveolar lavage fluid (BALF) eosinophils $\left({ }^{\star} P<0.001, n=10\right.$, recipient WT vs. recipient $C d 163^{-1-}$ mice). (c) Quantification of MCM. $\left({ }^{\star} P<0.001, n=10\right)$. Data are pooled from two independent experiments. Numbers of mice that were included in each experimental condition are shown.

CCR3. ${ }^{18}$ The eotaxin gene family comprises three genes in humans (CCL11, CCL24, and CCL26) and two in the mouse (CCL11 and CCL24). ${ }^{22}$ CCL11 (eotaxin-1) was initially identified as the major eosinophil chemotactic factor in allergen-challenged guinea pigs, while CCL24 (eotaxin-2) was cloned based upon sequence homology with known $\beta$-chemokines. ${ }^{27,28}$ Expression of both CCL11 and CCL2 4 is IL-13-dependent with CCL11 expression being restricted to lung tissue cells in the mouse, while CCL24 is primarily expressed by AMФs. ${ }^{29}$ Consistent with this, an OVA-induced model of murine airway inflammation has shown that CCL24 has a predominant role over CCL11 in mediating eosinophil recruitment to BALF, whereas CCL11 and CCL24 act in a synergistic manner to recruit eosinophils to lung tissue. Furthermore, CCL24 has an important role in mediating IL-13-induced airway eosinophilia.

Here, we identify a new mechanism by which CD163 expression by AMФs may attenuate the severity of eosinophilic inflammation in HDM-induced airway disease. First, we show that cell-surface expression of CD163 by AMФs is reduced in human subjects with asthma, which suggested that CD163 might participate in the regulation of airway inflammatory responses in the lung. The reduction in cell-surface expression of CD163 by AMФs occurred despite $71 \%$ of asthmatic subjects having received treatment with inhaled steroids, which are known to increase CD163 expression. ${ }^{12}$ This is consistent with a recent report that found sputum macrophages from asthmatic subjects expressed less CD163 than macrophages from healthy subjects. ${ }^{30}$ Next, we identified and characterized the function of CD163 in HDM-challenged $C d 163^{-/-}$mice. HDMs are a common environmental trigger and a major risk factor for the development of allergic asthma. ${ }^{31}$ In particular, we used $D$. pteronyssinus, which is one of the two predominant species of HDM, ${ }^{32}$ and found that $C d 163^{-/-}$mice have a phenotype of augmented HDM-induced eosinophilic pulmonary inflammation and MCM.

We then assessed the mechanisms mediating the augmented airway eosinophilia in HDM-challenged $C d 163^{-/-}$mice. We did not find evidence that the augmented airway eosinophilia in HDM-challenged $C d 163^{-/-}$mice occurred as a consequence of enhanced allergic sensitization or production of Th2 cytokines. Instead, the augmented eosinophilic airway inflammation appeared to be mediated by the increased production of CCL24, which is a C-C chemokine that induces the chemotaxis of eosinophils to the lung. In particular, HDM-challenged $C d 163^{-/-}$mice had significantly increased CCL24 in both BALF and the lung, whereas neither CCL11, CCL17, nor CCL22 was increased. Furthermore, $C d 163^{-1-}$ 

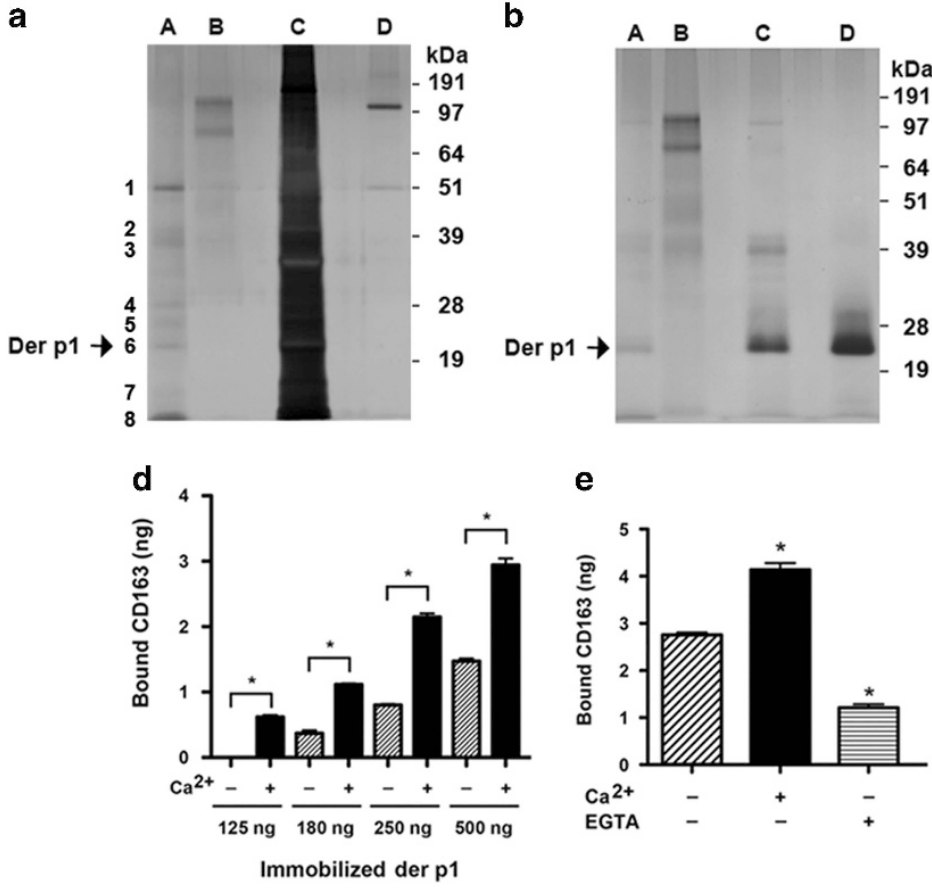

e

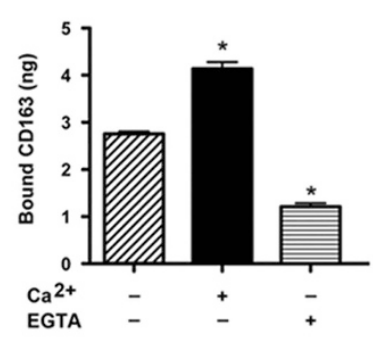

c

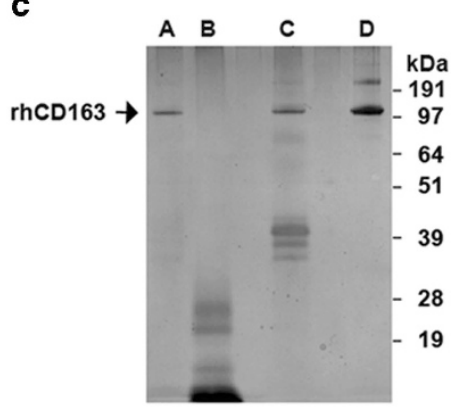

f

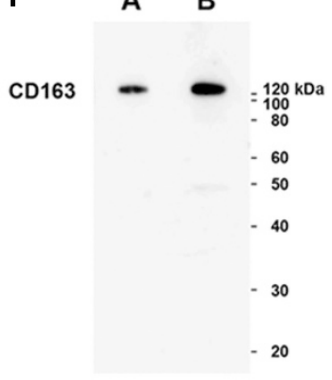

A B

g

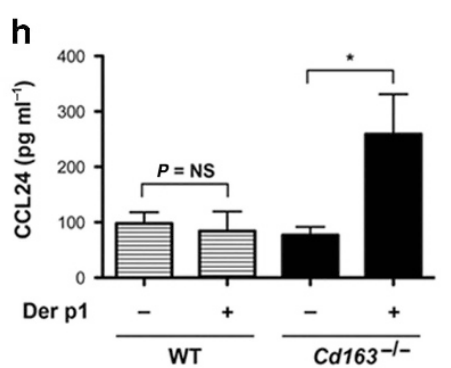

Figure 8 CD163 binds Dermatophagoides pteronyssinus peptidase 1 (Der p1). (a) Proteins in D. pteronyssinus extracts that bound to immobilized recombinant human CD163 (rhCD163) were eluted, resolved by SDS-PAGE and visualized by silver staining (lane A). Band \#6 was identified as D. pteronyssinus peptidase 1 (Der p1). Also shown are proteins that eluted from the rhCD163 resin in the absence of $D$. pteronyssinus extracts (lane B), proteins in D. pteronyssinus extracts that did not bind to immobilized rhCD163 (lane C) and rhCD163 alone (lane D). (b) Immobilized rhCD163 was incubated with purified Derp1 and eluted proteins were resolved by SDS-PAGE and visualized by silver staining. A protein corresponding to the molecular weight of Der p1 was eluted from immobilized rhCD163 (lane A). Proteins that were eluted in the absence of Der p1 (lane B), purified Der p1 proteins that did not bind to the immobilized rhCD163 resin (lane C) and Der p1 protein alone (lane D) are shown. (c) Immobilized Der p1 was incubated with rhCD163 and eluted proteins resolved by SDS-PAGE and visualized by silver staining. A protein corresponding to the molecular weight of rhCD163 was eluted from immobilized rhCD163 (lane A). Proteins that eluted from the immobilized rhCD163 resin in the absence of rhCD163 (lane B) and rhCD163 that did not bind to immobilized Der p1 (lane C) and rhCD163 alone (lane D) are shown. (d) Increasing amounts of purified Der p1 were bound to plastic and incubated with $120 \mathrm{ng}$ of rhCD163 with or without supplemental calcium $(5 \mathrm{mM})$. The amount of rhCD163 that bound to immobilized Der p1 increased in a doseresponsive manner $(n=3, P<0.0001)$. Binding of rhCD163 to immobilized Der 11 was calcium dependent $\left(n=3,{ }^{*} P<0.0001\right.$, supplemental calcium vs. no supplemental calcium). (e) $250 \mathrm{ng}$ of purified Der p1 was immobilized to plastic and incubated with $120 \mathrm{ng}$ of rhCD163 with or without supplemental calcium $(5 \mathrm{mM})$ or EGTA $(5 \mathrm{mM})$. The amount of rhCD163 that bound immobilized Der p1 was quantified $\left(n=4,{ }^{\star} P<0.0001\right.$, vs. PBS alone). (f) Immobilized Der 1 was incubated with human monocyte proteins. Bound proteins were eluted and western blots were performed using an anti-human CD163 antibody (lane A). For comparison, human monocyte proteins were subjected to western blotting in lane B. (g) Immobilized Der p1 was incubated with human monocyte proteins with or without supplemental calcium $(5 \mathrm{mM})$ or EGTA $(5 \mathrm{mM})$. Bound proteins were eluted and western blotting was performed using an anti-human CD163 antibody. (h) CCL24 secretion by bone marrow-derived macrophages stimulated with Der p1 $\left(20 \mu \mathrm{g} \mathrm{ml}{ }^{-1}\right)(n=6$, ${ }^{\star} P<0.05$ vs. medium alone). Data are representative of two or three independent experiments.

$\mathrm{AM} \Phi$ s that were re-stimulated ex vivo with HDM secreted increased amounts of CCL24 as compared with WT AMФs. This finding suggested that the augmented HDM-induced airway eosinophilia and MCM in $C d 163^{-/-}$mice occurred by a CCL24-dependent mechanism. This was confirmed by administration of a neutralizing anti-CCL24 antibody to HDM-challenged $C d 163^{-/-}$mice, which significantly reduced eosinophilic airway inflammation and MCM to levels similar to those found in HDM-challenged WT mice. Administration of the neutralizing anti-CCL24 antibody to WT mice, however, did not reduce either HDM-induced BAL eosinophils or MCM, which suggested that maximal responses in CD163-sufficient WT mice were not CCL24-dependent.

Our results also showed that the generation of AAMs in the setting of HDM-induced airway disease is not modified in the absence of CD163. There was, however, an increase in 


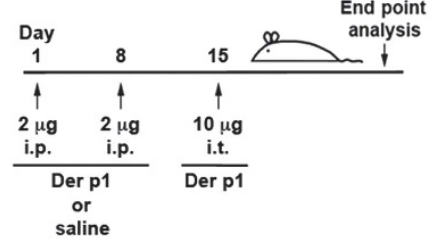

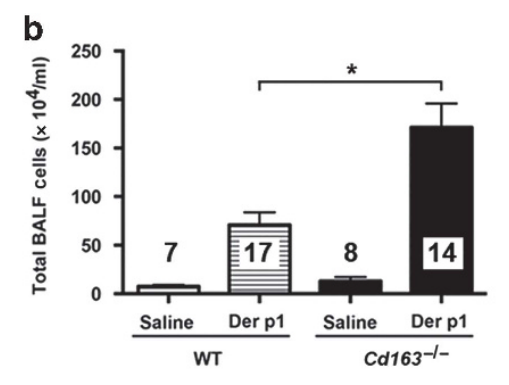

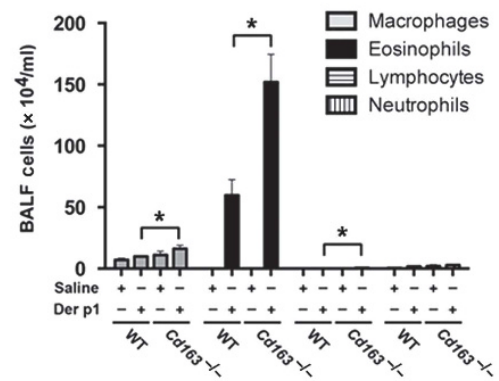

C

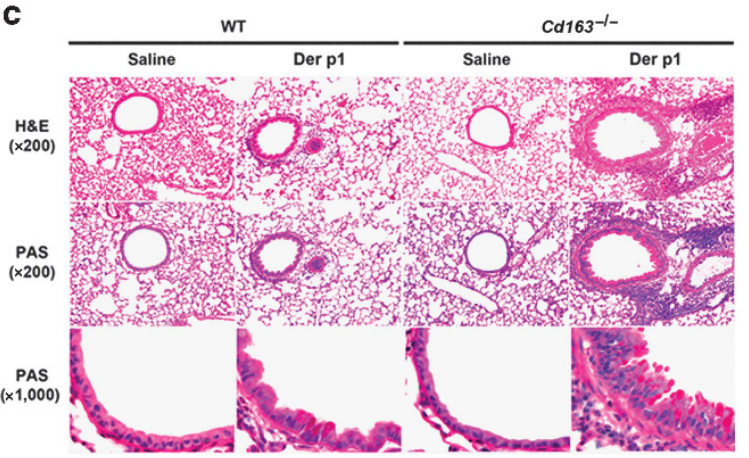

d

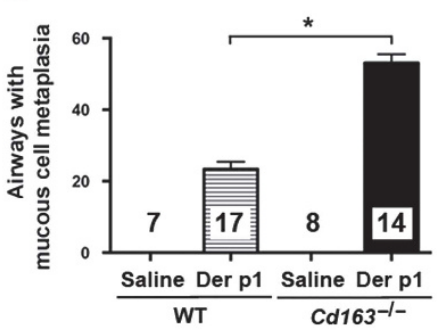

e

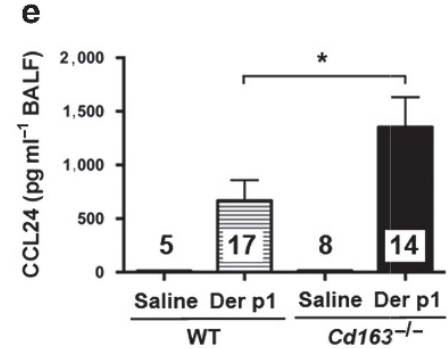

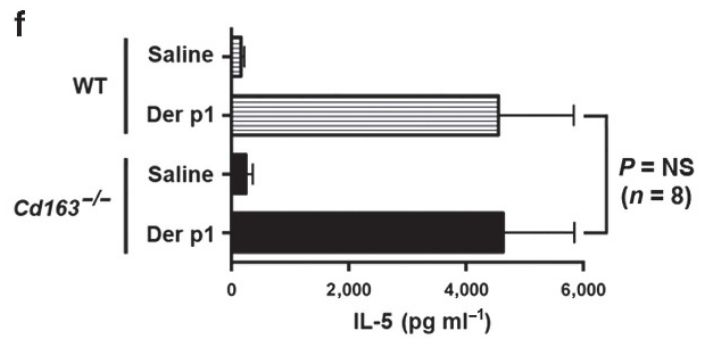

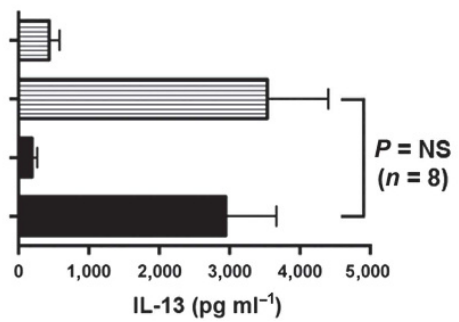

Figure 9 Eosinophilic airway inflammation and mucous cell metaplasia (MCM) are augmented in Dermatophagoides pteronyssinus peptidase 1 (Der p1)-challenged $\mathrm{Cd}_{163^{-1-}}$ mice. (a) WT and $\mathrm{Cd}_{163^{-/-}}$mice were sensitized by intraperitoneal injection of Der p1 or saline on days 1 and 8 and challenged with intratracheal Der p1 on day 15 . End points were analyzed $72 \mathrm{~h}$ later. (b) Total bronchoalveolar lavage fluid (BALF) inflammatory cells and inflammatory cell types $\left(n=7-17\right.$ mice, $\left.{ }^{*} P<0.05\right)$. (c) Representative lung histologic sections from WT and $C d 163^{-1-}$ mice that had been challenged with saline or Der p1 and stained with hematoxylin and eosin $(\mathrm{H} \& \mathrm{E})(\times 200)$ or periodic acid Schiff $(\mathrm{PAS})(\times 200$ and $\times 1,000)$. (d) Quantification of MCM ( $n=7-17$ mice, $\left.{ }^{\star} P<0.0001\right)$. $30.6 \pm 0.9$ airways were counted per mouse. (e) BALF CCL24 levels $\left(n=5-17\right.$ mice, $\left.{ }^{*} P<0.05\right)$. (f) Ex vivo cultures of mediastinal lymph node cells from Der p1-challenged WT and $C d 163^{-/-}$mice were re-stimulated with Der p1 $\left(10 \mu \mathrm{g} \mathrm{ml}{ }^{-1}\right)$ or saline, as a control, and cytokine secretion was quantified $(n=8)$. Panels $(\mathbf{b}-\mathbf{f})$ are pooled data from two independent experiments. Numbers of mice that were included in each experimental condition are shown.

cell-surface expression of the AAM marker, CD206 (Mrc1, mannose receptor), on cells from HDM-challenged $C d 163^{-1-}$ mice, as well as an increase in BALF levels of Chi3 $\mathrm{L} 3 / 4(\mathrm{Ym} 1 / 2)$, which is a product of AAMs. ${ }^{3}$ The importance of AAMs in the pathogenesis of HDM-induced airway inflammation, however, is unclear as HDM-challenged conditional knockout mice that lack the IL-4 receptor $\alpha$ chain on $\mathrm{LysM}^{+}$macrophages do not have reductions in BALF eosinophil numbers, which suggests that AAMs may only be a marker of Th2 cytokine levels. ${ }^{33}$

Next, we investigated the mechanism by which CD163 attenuates CCL24 production by HDM-stimulated AMФs. We hypothesized that CD163 might serve as a receptor for an HDM protein, which would be consistent with its function as a scavenger receptor. ${ }^{6-9,11} \mathrm{HDM}$ is a complex aeroallergen that comprises mite-derived proteins and fecal pellets, as well as lipopolysaccharide and fungal spores. ${ }^{34,35}$ At least 19
D. pteronyssinus proteins have been characterized as allergens that are bound by IgE. We utilized immobilized recombinant human CD163 to identify Der p1 as a binding partner by mass spectroscopy. The ability of CD163 to bind Der p1 was confirmed by in vitro pull-down experiments using recombinant and purified proteins, which showed that the interaction was calcium-dependent. This is consistent with the requirement of calcium for binding of hemoglobin-haptoglobin complexes to CD163. ${ }^{20}$ Similarly, purified Der p1 was able to pull-down CD163 from human monocyte lysates.

Der p1 is a $25-\mathrm{kDa}$ glycoprotein expressed in the mite gut, which suggests that its endogenous function is related to digestion. ${ }^{36,37}$ Der $\mathrm{p} 1$ is a member of the group 1 allergens, which are typical cysteine proteases that share structural similarity to papain. ${ }^{32}$ Group 1 allergens are released into fecal pellets, where Der $\mathrm{p} 1$ is found in high concentrations that range 

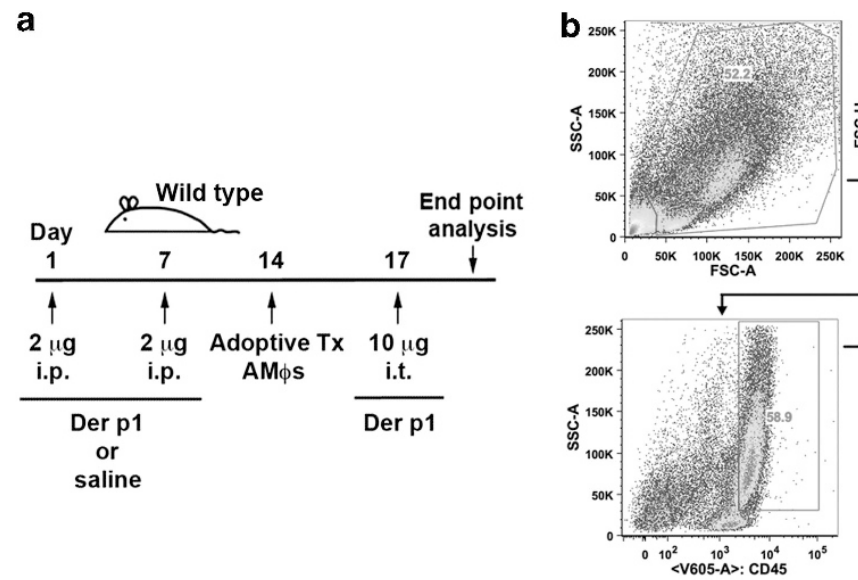
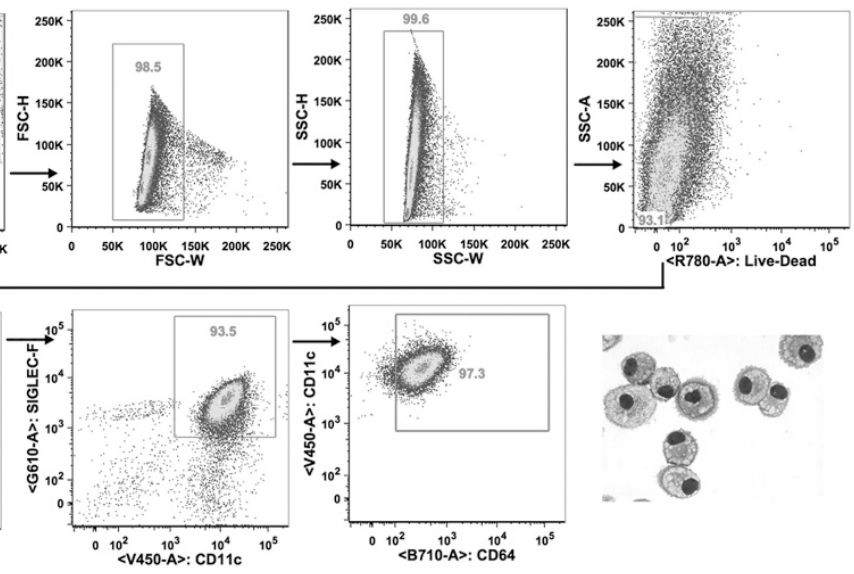

C
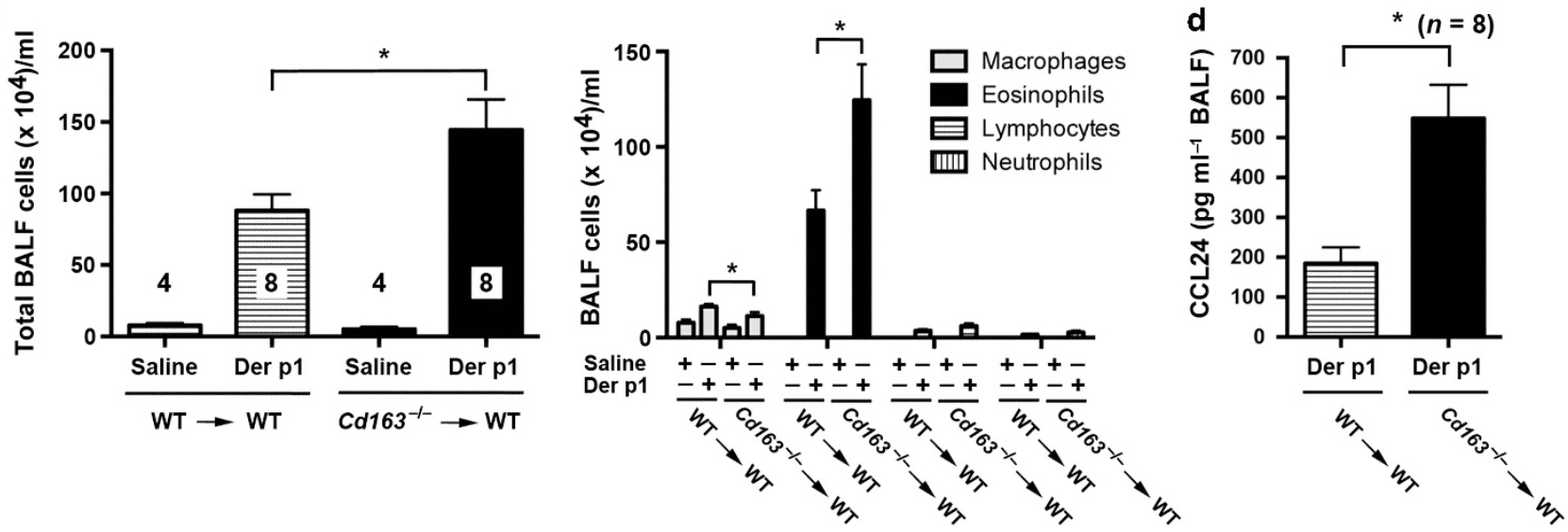

Figure 10 The adoptive transfer of alveolar macrophages (AMФs) from donor $C d 163^{-1-}$ mice enhances Dermatophagoides pteronyssinus peptidase 1 (Der p1)-induced increases in eosinophilic airway inflammation and mucous cell metaplasia (MCM) in recipient wild-type (WT) mice. (a) WT mice were sensitized by intraperitoneal (i.p.) injection of Der p1 or saline, as a control, on days 1 and 7 , followed by the intranasal adoptive transfer of $1 \times 10^{5} \mathrm{AM} \Phi$ s from naïve donor WT or $C d 163^{-1-}$ mice on day 14 . All mice received an intratracheal Der $1(10 \mu \mathrm{g})$ challenge on day 17 and end points were analyzed on day 20. (b) Gating strategy for sorting of naive murine alveolar macrophages in bronchoalveolar lavage fluid (BALF). Cellular debris was excluded using a forward light scatter/side scatter plot and doublets were excluded using width parameter on forward light scatter (FSC) and side light Scatter (SSC) properties. CD $45^{+}$cells that co-expressed CD11c, Siglec-F, and CD64 were identified as AMФs. A microscopic image of sorted CD45 ${ }^{+} / \mathrm{CD}_{11 \mathrm{c}}{ }^{+} / \mathrm{Siglec}-$ $\mathrm{F}^{+} / \mathrm{CD} 64^{+}$cells shows a cellular population possessing typical characteristics of AM $\Phi$ s. (c) Total BALF inflammatory cells and inflammatory cell types ( $n=4-8$ mice, ${ }^{*} P<0.05$, donor Cd163 ${ }^{-l-}$ AMФs vs. donor WT AMФs). (d) BALF CCL24 levels from Der p1-challenged recipient mice ( $n=8$ mice, $P=0.0016$, donor $C d 163^{-1-}$ AMФs vs. donor WT AMФs, unpaired $t$ test). (c, d) Representative data from one of three independent experiments are shown. Numbers of mice that were included in each experimental condition are shown. The same numbers of mice are shown for both analyses in (c).

from 100 to $10,000 \mathrm{ng} \mathrm{g}^{-1}$ of dust. $^{32,35}$ Der p1 is one of the major allergens in $D$. pteronyssinus that is targeted by as much as $70 \%$ of the circulating IgE in atopic subjects. ${ }^{19,35}$ Furthermore, Der $\mathrm{p} 1$ has been shown to promote Th2 responses by selectively reducing IFN- $\gamma$ production, as well as by mediating the cleavage of multiple cell surface molecules, including the low-affinity IgE Fc receptor (CD23), the IL-2 receptor (CD25) $\alpha$ subunit, DC-SIGN (CD209), and DC-SIGNR (CD299). ${ }^{38-42}$ Der p1 also disrupts intercellular tight junctions in the airway by cleaving the adhesion proteins occludin and claudin-1, which facilitates transepithelial movement of Der $\mathrm{p} 1$ to antigenpresenting DCs. ${ }^{43}$ In airway epithelial cells, Der p1 induces IL-6 and IL- 8 secretion, as well as activates NF- $\kappa$ B, ERK1/2, p38 MAPK, and JNK signaling. ${ }^{44,45}$ Finally, Der $\mathrm{p} 1$ binds mannose receptors on human monocyte-derived DCs, which may facilitate allergen internalization. ${ }^{37}$ Here, we show that Der p1 induced CCL24 production by $C d 163^{-/-}$BMMФs, but not from WT BMMФs. Furthermore, $C d 163^{-/-}$mice that had been sensitized and challenged with Der p1 had a similar phenotype of increased airway eosinophilia, MCM and CCL24 production as was seen when $C d 163^{-/-}$mice were sensitized and challenged with HDM. In addition, Der p1-challenged WT mice that received the adoptive transfer of $C d 163^{-/-}$AMФs had significantly increased eosinophilic airway inflammation and BALF CCL24 levels as compared with recipients of WT AMФs. It is important to point out, however, that we cannot exclude a role for other cells in the lung that have also been reported to produce CCL24, such as neutrophils and airway epithelial cells, in mediating the phenotype of increased eosinophilic airway inflammation in Der p1-challenged $C d 163^{-/^{-}}$mice. ${ }^{46,47}$ Finally, since CD163 functions as a scavenger receptor with multiple known ligands, we also hypothesized that the phenotype of allergen-challenged Cd163 ${ }^{-/-}$mice might not be specific for Der p1 and could 
possibly be seen when $C d 163^{-1-}$ mice are sensitized and challenged with other allergens. Consistent with this, we found that OVA-challenged $C d 163^{-1-}$ mice have a similar inflammatory phenotype as HDM-challenged $C d 163^{-1-}$ mice with increases in both BALF eosinophils and CCL24 (Supplementary Figure 2).

In summary, we have shown that CD163 binds the major HDM allergen, Der p1, in a calcium-dependent manner and that macrophages from $C d 163^{-1-}$ mice produce increased quantities of CCL24 when stimulated with HDM or Der p1. Furthermore, HDM-challenged $C d 163^{-1-}$ mice display a phenotype of increased eosinophilic airway inflammation and MCM that occurs by a CCL24-dependent mechanism. Thus, we propose that the reduced expression of CD163 by AMФs from asthmatic patients may be associated with enhanced eosinophilic airway inflammation in response to inhalation of the HDM antigen, Der p1.

\section{METHODS}

Human samples. Informed consent was obtained as per NHLBI protocol 99-H-0076. Normal individuals did not have airway hyperreactivity to inhaled methacholine challenge, while asthmatic subjects had either a positive bronchodilator response to an aerosolized short-acting $\beta_{2}$-agonist or airway hyperreactivity to inhaled methacholine. Allergy was defined by at least one positive skin test to short ragweed, grass mixture, cat dander, cockroach (German and American), Dermatophagoides farinae, or Aspergillus fumigatus or a prior history of positive allergy skin testing. Skin testing was performed using a Multi-Test II applicator (provided as a generous gift from Lincoln Diagnostics, Decatur, IL). All subjects were clinically stable at the time of the bronchoscopy. Exclusion criteria included an active respiratory tract infection and current cigarette smoking. Total BALF cells were counted using a hemocytometer and differential cell counts were performed using Diff-Quik-stained cytospin slides (Siemens, Deerfield, IL).

Confocal immunofluorescence microscopy. Human BALF cell cytospin slides were fixed in $4 \%$ paraformaldehyde, incubated in blocking buffer (Aurion Blocking Solution, Electron Microscopy Sciences, Hatfield, PA) and reacted overnight with mouse anti-human CD68 (1:50 dilution, R\&D Systems, Minneapolis, MN) and rabbit anti-human CD163 antibodies (1:50 dilution, Enzo Life Sciences, Farmingdale, NY) diluted in $0.1 \%$ Aurion BSA-c (Electron Microscopy Sciences). Slides were washed five times in PBS, incubated with speciesspecific secondary antibodies conjugated to Alexa Fluor 488 or Alexa Fluor 568 (Life Technologies, Grand Island, NY) at a 1:200 dilution, washed five times, mounted using Vectashield mounting medium with DAPI (Vector Laboratories, Burlingame, CA) and visualized utilizing a Zeiss LSM 510 UV confocal microscope (Carl Zeiss Microscopy GmbH, Jena, Germany).

Flow cytometry. Human BALF cells were washed and suspended in flow cytometry staining buffer (calcium- and magnesium-free PBS with $1 \%$ bovine serum albumin (BSA) and $0.25 \mathrm{mM}$ EDTA). Cells were incubated with mouse anti-human CD45 PECy5 (eBioscience, San Diego, CA), mouse anti-human CD14 BV605 (BD Biosciences, Franklin Lakes, NJ), mouse anti-human CD68 PerCPCy5.5 (Biolegend, San Diego, CA), mouse anti-human CD163 APC (Biolegend), and fixable viability dye eFluor 450 (eBioscience) for $45 \mathrm{~min}$, washed with flow cytometry staining buffer and re-suspended in buffer containing $1 \%$ paraformaldehyde. Cells were acquired on a LSRII equipped with 407, 488, 532, and 633 LASER lines using DIVA 6.1.2 software (BD Biosciences, San Jose, CA). Data were analyzed using FlowJo software version 9.1.5 (Treestar, San Carlos, CA).
Murine BALF cells were suspended in flow cytometry staining buffer (eBioscience) containing $1 \%$ mouse and rat serum and incubated with rat anti-mouse CD45 BV605 (BD Biosciences), hamster anti-mouse CD11c PerCp Cy5.5 (BD Biosciences), rat anti-mouse Siglec-F BB515 (BD Biosciences), anti-mouse CD64 (Fc $\gamma \mathrm{RI})$ PE-Cy7 (Biolegend), and rat anti-mouse CD206 BV 650 (Biolegend) for $45 \mathrm{~min}$ on ice. Cells were re-suspended in PBS containing 1\% paraformaldehyde and events were acquired on a LSRII (BD Biosciences). Cellular debris was excluded using a forward light scatter/side scatter plot. A macrophage gate was determined based upon light-scatter properties and $\mathrm{CD} 45^{+} / \mathrm{CD} 11 \mathrm{c}^{+} /$Siglec-F ${ }^{+} / \mathrm{CD} 64^{+}$AMФs were analyzed for $\mathrm{CD}^{2} 06^{+}$expression (Supplementary Figure 1).

Cd163 ${ }^{-1-}$ mice. $C d 163^{-/-}$mice on a C57BL/6 genetic background were generated from Cd163 $3^{\text {tml(KOMP)Vlcg }}$ embryos obtained from the Knockout Mouse Project at the University of California, Davis, CA. Cd163 ${ }^{\text {tml(KOMP)Vlcg }}$ embryos have a 24,636 base pair deletion from nucleotides $124,254,756$ to $124,279,391$ of chromosome 6 . The Cd163 ${ }^{\text {tm1(KOMP)Vlcg }}$ embryos were created from ES cell clone Cd163_BA3, generated by Regeneron Pharmaceuticals (Tarrytown, $\mathrm{NY}$ ) and made into live mice at the Jackson Laboratory (Bar Harbor, ME). ${ }^{48}$ Wild-type C57BL/6 mice were from Taconic Labs (Hudson, $\mathrm{NY}$ ). Both female and male mice that were matched by gender were used for experiments.

Genotyping of $\mathrm{Cd163}^{-1-}$ mice. The targeted deletion of the Cd163 gene was confirmed by PCR of genomic DNA and qRT-PCR of lung mRNA. SU (5'-GTGTTCCAAAGTGGGAGGAG-3') and LacZRev (5'-GTCTGTCCTAGCTTCCTCACTG-3') primers were used to confirm the presence of the targeting vector in $C d 163^{-/-}$mice, whereas TDF (5'-TCATTCCAGGAGAAGTGCCC- $\left.3^{\prime}\right)$ and TDR (5'-CCAAGGCAAATCCCTCTCAG- $\left.3^{\prime}\right)$ primers were used to confirm the absence of introns $15-16$ of the $C d 163$ gene in $C d 163^{-1-}$ mice. A Taqman probe directed against the boundary of exons 6 and 7 (Mm00474091_m1, Applied Biosystems/Life Technologies) was used for qRT-PCR to confirm the absence of Cd163 mRNA expression in the lungs of $C d 163^{-1-}$ mice.

Murine models of HDM- and Der p1-induced airway disease. Experimental protocols were approved by the NHLBI Animal Care and Use Committee. D. pteronyssinus extract, referred to as HDM, was purchased from Greer Laboratories (Lenoir, NC) and contained $\leq 50$ units of lipopolysaccharide per mg of HDM protein, which equated to administration of $\leq 5 \mathrm{pg}$ of lipopolysaccharide with each $\mu \mathrm{g}$ of HDM. $^{49}$ (i) Intranasal HDM sensitization and challenge model. Six- to eight-week-old WT C57BL/6 and $\mathrm{Cd}_{163^{-1-}}$ mice received daily intranasal challenges of HDM $(25 \mu \mathrm{g})$ or saline, in a volume of $10 \mu \mathrm{l}, 5$ days a week for 5 weeks. End points were analyzed $24 \mathrm{~h}$ after the last challenge. (ii) Intraperitoneal HDM sensitization and intranasal challenge model for AAM experiments. Eight- to ten-week-old WT and $C d 163^{-1-}$ mice were sensitized on days 1 and 4 by intraperitoneal injection of HDM $\left(50 \mu \mathrm{g} \mathrm{ml}^{-1}\right)$ emulsified in $60 \mu \mathrm{l}$ of $2 \%$ Alhydrogel adjuvant (Invivogen, San Diego, CA ) plus $140 \mu$ l of sterile PBS. On day 8 , all mice received a single intranasal challenge of HDM $(100 \mu \mathrm{g})$. BALF cells were collected on day 10. (iii) CCL24 inhibition experiments. In all, $5 \mu \mathrm{g}$ of a neutralizing, monoclonal rat anti-mouse CCL24 antibody (MAB528) or a monoclonal rat $\operatorname{IgG}_{2 \mathrm{~A}}$ isotype control antibody (R\&D Systems) were administered to the nares daily, 3 days per week, concurrent with HDM challenges for 5 weeks. End points were analyzed $24 \mathrm{~h}$ after the last challenge. (iv) Adoptive transfer of HDM-pulsed BMMФs. Bone marrow cells from donor WT and $\mathrm{Cd}_{163^{-1-}}$ mice were harvested on day 1 and cultured in GM-CSF $\left(20 \mathrm{ng} \mathrm{ml}^{-1}\right)$ until day 9, when cells were pulsed with HDM $\left(100 \mu \mathrm{g} \mathrm{ml}^{-1}\right)$ or saline as a control. On day $10, \mathrm{CD}_{11 \mathrm{c}}{ }^{+} / \mathrm{MHCII}^{+}$/ Siglec-F BMDCs were isolated by flow sorting and $1 \times 10^{5}$ BMDCs were adoptively transferred by intranasal administration to recipient WT mice, which received daily intranasal instillations of $\mathrm{HDM}(50 \mu \mathrm{g})$ on days 23 through 26. End points were analyzed on day 27. (v) 
Adoptive transfer of HDM-pulsed MLN dendritic cells. WT and $C d 163^{-/-}$mice were pulsed with $\operatorname{HDM}(100 \mu \mathrm{g})$ or saline on day 1 and MLNs were harvested on day $4 . \mathrm{CD}_{11 \mathrm{c}^{+}} / \mathrm{MHCII}^{+} /$Siglec-F ${ }^{-} \mathrm{DCs}$ were isolated by flow sorting and $2.5 \times 10^{4}$ cells were administered to the nares of recipient WT mice, which then received daily intranasal HDM challenges $(25 \mu \mathrm{g})$ on days 9 through 14 and end points were analyzed on day 15. (vi) Adoptive transfer of splenic $\mathrm{CD} 4^{+} \mathrm{T}$ cells. Eight- to ten-week-old WT C57BL/6 mice were sensitized on days 1 and 7 by intraperitoneal injection of saline or HDM $\left(100 \mu \mathrm{g} \mathrm{ml}^{-1}\right)$ emulsified in $60 \mu \mathrm{l}$ of $2 \%$ Alhydrogel adjuvant (Invivogen) plus $140 \mu \mathrm{l}$ of sterile PBS. On day $14, \mathrm{CD}^{+}{ }^{+} \mathrm{T}$ cells were purified from the spleens of sensitized mice using the EasySep Mouse CD4 ${ }^{+}$T Cell Isolation kit (StemCell Technologies, Vancouver, BC, Canada) to a purity of $95 \%$, which was verified by flow cytometry, and 2 million CD $4{ }^{+} \mathrm{T}$ cells were adoptively transferred in $100 \mu \mathrm{l}$ of PBS via intraperitoneal administration to recipient WT and $C d 163^{-1-}$ mice. Recipient mice received intranasal HDM $(50 \mu \mathrm{g})$ challenges on days $19,21,23$, and 25 and end points were analyzed on day 27. (vii) Der p1 model. Der p1 experiments were performed using a modification of a previously published protocol. ${ }^{17}$ Mice were sensitized by intraperitoneal injection of saline $(100 \mu \mathrm{l})$ with or without $2 \mu \mathrm{g}$ of LoTox Der p1 (Indoor Biotechnologies, Charlottesville, VA) on days 1 and 8 . On day $15,10 \mu \mathrm{g}$ of LoTox Der p1 was administered via intratracheal instillation in $40 \mu \mathrm{l}$ of saline. End points were analyzed $72 \mathrm{~h}$ after the last challenge. (viii) AM $\Phi$ adoptive transfer experiments. Recipient mice were sensitized by intraperitoneal injection of LoTox Der p1 $(2 \mu \mathrm{g})$, or saline as a control, on days 1 and 7. On day 14, bronchoalveolar lavage was performed on naïve donor mice using ice-cold PBS without magnesium chloride and calcium chloride plus $2 \mathrm{~mm}$ EDTA. Viable CD $45^{+} / \mathrm{CD} 11 \mathrm{c}^{+} /$Siglec$\mathrm{F}^{+} / \mathrm{CD} 64^{+} \mathrm{AM} \Phi$ s in BALF were isolated by flow sorting and $1 \times 10^{5}$ cells were adoptively transferred to recipient mice by intranasal instillation. Recipient mice were challenged by intratracheal LoTox Der p1 $(10 \mu \mathrm{g})$ administration on day 17 and end points were analyzed on day 20. Analyses of BALF cells and lung histology were performed as previously described. ${ }^{49}$

HDM-specific IgE. Serum HDM-specific IgE was measured by incubating plates overnight with $0.01 \% \mathrm{HDM}$ in PBS and blocked with $1 \%$ BSA before addition of serum for $1 \mathrm{~h}$. Serum was depleted of IgG by incubating with protein $\mathrm{G}$ agarose (ThermoFisher Scientific, Waltham, MA) overnight at $4{ }^{\circ} \mathrm{C}$ before analysis. Following six washes with PBS plus $0.05 \%$ Tween-20, biotinylated anti-mouse IgE (Pharmingen, San Jose, CA) was added for $1 \mathrm{~h}$. Plates were washed six times before addition of streptavidin-HRP (R\&D Systems) for $30 \mathrm{~min}$. TMB substrate was added for $30 \mathrm{~min}$ to determine the quantity of HDMspecific antibody.

Enzyme-linked immunosorbent assays. Quantification of CCL11, CCL24, and Chi3L3/4 was performed using Duoset ELISA kits from R\&D Systems.

Western blotting. Lung proteins $(12.5 \mu \mathrm{g})$ were separated by SDSPAGE using 10\% Bis-Tris Nupage gels (Life Technologies). The antibodies against Muc5AC (1:500 dilution) and $\beta$-actin (1:3,000 dilution) were from Abcam (Cambridge, MA). Membranes were stripped using the Re-Blot recycling kit (Chemicon International, Temecula, CA). Densitometry was performed using NIH ImageJ software (NIH, Bethesda, MD).

Airway hyperreactivity. Airway resistance to increasing doses of nebulized methacholine was directly measured in anesthetized mice that were mechanically ventilated using an Elan RC Fine Pointe system (Buxco, Wilmington, NC), as previously described. ${ }^{49}$

HDM-specific re-stimulation of MLN cultures and measurement of Th2 cytokine production. MLNs were excised from HDM-challenged WT and $C d 163^{-1-}$ mice and single cell suspensions were generated by passage through a $100-\mu \mathrm{m}$ strainer, followed by lysis of red blood cells using ACK buffer. Cells were suspended in RPMI-1640 medium containing $10 \%$ fetal calf serum, penicillin ( 50 units $\mathrm{ml}^{-1}$ ), streptomycin $\left(50 \mu \mathrm{g} \mathrm{ml}^{-1}\right)$, and L-glutamine $(2 \mathrm{~mm})$ and $4 \times 10^{6}$ cells per well were cultured in 96-well plates with " $U$ "-shaped bottoms. Cells were stimulated with $\operatorname{HDM}\left(100 \mu \mathrm{g} \mathrm{ml}^{-1}\right)$, Der p1 $\left(10 \mu \mathrm{g} \mathrm{ml}^{-1}\right)$, or saline (as a control) for $96 \mathrm{~h}$ and medium was collected and analyzed for cytokines using ELISAs with a limit of sensitivity of $9.4 \mathrm{pg} \mathrm{ml}^{-1}$ for IFN- $\gamma, 15.6 \mathrm{pg} \mathrm{ml}^{-1}$ for IL-17A, $31.25 \mathrm{pg} \mathrm{ml}^{-1}$ for IL-5, and $62.5 \mathrm{pg} \mathrm{ml}^{-1}$ for IL-13 (R\&D Systems).

AM $\Phi$ isolation and HDM re-stimulation. $1 \times 10^{5}$ BALF cells from HDM-challenged WT and Cd163 $3^{-1-}$ mice were seeded in 96-well tissue culture plates or in Lab-Tek chamber slides and AMФs were allowed to adhere for $2 \mathrm{~h}$ in RPMI-1640 containing 10\% FBS. Nonadherent cells were removed by washing with PBS. Manual counting of Diff-Quik stained slides revealed that $92 \pm 0.3 \%$ of isolated cells were AMФs $(n=3)$. AMФs were re-stimulated with $500 \mu \mathrm{g} \mathrm{ml}^{-1}$ of HDM or medium for $24 \mathrm{~h}$ and CCL24 secretion was quantified by ELISA.

Proteomic identification of Der p1 binding to CD163. In all, $10 \mu \mathrm{g}$ of recombinant human CD163 protein (R\&D Systems), D. pteronyssinus extract or purified Der p1 (Indoor Biotechnologies, Charlottesville, VA) was covalently immobilized to an aldehyde-activated $4 \%$ beaded agarose resin (Pierce Direct IP Kit, Thermo Fisher Scientific) for $2 \mathrm{~h}$ and blocked with $1 \%$ chicken egg white albumin (Sigma-Aldrich, St Louis, MO). Resin-immobilized CD163 or purified Der p1 was incubated with $10 \mu \mathrm{g}$ of pre-cleared $D$. pteronyssinus protein extract, purified Der p1 or recombinant human CD163 overnight, washed six times with $0.1 \%$ Triton X-100, $50 \mathrm{~mm}$ Tris, $\mathrm{pH} 7.5$, and $120 \mathrm{~mm} \mathrm{NaCl}$ (Sigma-Aldrich) and interacting proteins were eluted, resolved by SDS-PAGE using 10\% Bis-Tris Nupage gels and visualized with the SilverQuest Silver Staining Kit (Life Technologies). Resins to which $10 \mu \mathrm{g}$ of chicken egg white albumin had been immobilized served as controls for background non-specific binding. Excised bands were destained and subjected to trypsin digestion, as previously described, before analysis by mass spectrometry using the LTQ Orbitrap Velos mass spectrometer (Thermo Fisher Scientific, San Jose, CA).$^{50}$ The raw file generated by the Velos was analyzed using Proteome Discoverer v1.3 software (Thermo Fisher Scientific) using the Mascot search engine (v2.3) (Matrix Science, Boston, MA). The Mascot search criteria were set to: database, Swiss-Prot (Swiss Institute of Bioinformatics); taxonomy, Eukaryota (eukaryotes); enzyme, trypsin; miscleavages, 3; variable modifications, oxidation (M), deamidation (NQ); fixed modifications, carbamidomethyl (C), MS peptide tolerance $10 \mathrm{ppm}$; MS/MS tolerance as $0.8 \mathrm{Da}$. The peptide confidence false discovery rat was set to less than $1 \%$.

CD163 binding to immobilized Der p1. Plastic 96-well plates were coated with purified Der $\mathrm{p} 1$ and blocked with $1 \%$ BSA dissolved in PBS. Recombinant human CD163 (R\&D Systems) (120 ng) was added to the Der p1-coated plates overnight, washed three times with $0.05 \%$ Tween-20 in PBS, and the quantity of CD163 that bound to the immobilized Der p1 was quantified using a CD163 immunoassay kit (R\&D Systems) with a horseradish peroxidase-conjugated anti-CD163 antibody. Non-specific binding of the anti-CD163 antibody to Der p1coated plates in the absence of CD163, as well as background related to the immobilized Der p1 protein in the absence of the anti-CD163 antibody were subtracted from the reported values.

Immunoprecipitation of human monocyte CD163. Elutriated human monocytes were provided under an IRB-approved protocol (01-CC0168) by the NIH Department of Transfusion Medicine, Clinical Center. Cells were lysed in buffer containing $0.1 \%$ Triton X-100, $50 \mathrm{~mm}$ Tris, $\mathrm{pH} 7.5$, and $120 \mathrm{~mm} \mathrm{NaCl}$ supplemented with Complete protease inhibitor (Thermo Fisher Scientific). In all, $300 \mu \mathrm{g}$ of protein lysates, with or without $5 \mathrm{~mm}$ calcium or $5 \mathrm{~mm}$ EGTA, was incubated overnight with $10 \mu \mathrm{g}$ of purified Der p1 that had been immobilized to an aldehyde-activated beaded agarose resin (Pierce Direct IP Kit, Thermo Fisher Scientific) and washed six times with cold lysis buffer. Eluted 
proteins were resolved by western blotting and CD163 was detected using a mouse monoclonal anti-CD163 antibody (MAB1607) from R\&D Systems.

Bone marrow-derived macrophage cultures. Bone marrow cells from $C d 163^{-1-}$ mice and WT mice were cultured in RPMI-1640 containing $10 \% \mathrm{FBS}, 2 \mathrm{mM}$ L-glutamine, $100 \mathrm{U} \mathrm{ml}^{-1}$ penicillin, $100 \mu \mathrm{g} \mathrm{ml}^{-1}$ streptomycin, $0.05 \mathrm{M} \mathrm{2-ME}$, and recombinant mouse M-CSF (20 ng ml ${ }^{-1}$, Biolegend) for 6 days. ${ }^{21}$ Cells were treated with IL-4 (10 ng ml ${ }^{-1}$ ) (Biolegend) for $48 \mathrm{~h}$ to induce CCL24 expression before stimulation with purified Der p1 $\left(20 \mu \mathrm{g} \mathrm{ml}^{-1}\right)$ for $48 \mathrm{~h}$ and CCL24 release into medium was quantified by ELISA.

Statistics. Data are presented as mean \pm s.e.m. Results were analyzed using a one-way ANOVA with Bonferroni's multiple comparison test (GraphPad Prism version 5.0a, La Jolla, CA), except where indicated that a paired or unpaired $t$ test or a Mann-Whitney test were utilized. A $P$-value of $<0.05$ was considered as significant.

SUPPLEMENTARY MATERIAL is linked to the online version of the paper at http://www.nature.com/mi

\section{ACKNOWLEDGMENTS}

We thank Dr Grzegorz Piszczek from the NHLBI Biophysics Core Facility, $\operatorname{Dr}$ Christian A. Combs and $\mathrm{Dr}$ Daniela Malide, from the NHLBI Light Microscopy Core Facility, for their advice and support, and Dr Martha Vaughan and Dr Joel Moss for their helpful discussions. This work was funded by the Division of Intramural Research, NHLBI.

\section{DISCLOSURE}

The authors declared no conflict of interest.

(c) 2016 Society for Mucosal Immunology

\section{REFERENCES}

1. Murray, P.J. \& Wynn, T.A. Protective and pathogenic functions of macrophage subsets. Nat. Rev. Immunol. 11, 723-737 (2011).

2. Yang, M., Kumar, R.K., Hansbro, P.M. \& Foster, P.S. Emerging roles of pulmonary macrophages in driving the development of severe asthma. $\mathrm{J}$. Leukoc. Biol. 91, 557-569 (2012).

3. Murray, P.J. et al. Macrophage activation and polarization: nomenclature and experimental guidelines. Immunity 41, 14-20 (2014).

4. Law, S.K. et al. A new macrophage differentiation antigen which is a member of the scavenger receptor superfamily. Eur. J. Immunol. 23, 2320-2325 (1993).

5. Ritter, M., Buechler, C., Langmann, T. \& Schmitz, G. Genomic organization and chromosomal localization of the human CD163 (M130) gene: a member of the scavenger receptor cysteine-rich superfamily. Biochem. Biophys. Res. Commun 260, 466-474 (1999).

6. Van Gorp, H., Delputte, P.L. \& Nauwynck, H.J. Scavenger receptor CD163, a Jack-of-all-trades and potential target for cell-directed therapy. Mol. Immunol. 47, 1650-1660 (2010).

7. Kristiansen, M. et al. Identification of the haemoglobin scavenger receptor. Nature 409, 198-201 (2001).

8. Fabriek, B.O. et al. The macrophage CD163 surface glycoprotein is an erythroblast adhesion receptor. Blood 109, 5223-5229 (2007).

9. Fabriek, B.O. et al. The macrophage scavenger receptor CD163 functions as an innate immune sensor for bacteria. Blood 113, 887-892 (2009).

10. Bover, L.C. et al. A previously unrecognized protein-protein interaction between TWEAK and CD163: potential biological implications. J. Immunol. 178, 8183-8194 (2007).

11. Sanchez-Torres, C. et al. Expression of porcine CD163 on monocytes/ macrophages correlates with permissiveness to African swine fever infection. Arch. Virol. 148, 2307-2323 (2003).

12. Hogger, P., Dreier, J., Droste, A., Buck, F. \& Sorg, C. Identification of the integral membrane protein RM3/1 on human monocytes as a glucocorticoid-inducible member of the scavenger receptor cysteine-rich family (CD163). J. Immunol. 161, 1883-1890 (1998).
13. Sulahian, T.H. et al. Human monocytes express CD163, which is upregulated by IL-10 and identical to p155. Cytokine 12, 1312-1321 (2000).

14. Philippidis, P. et al. Hemoglobin scavenger receptor CD163 mediates interleukin-10 release and heme oxygenase- 1 synthesis: antiinflammatory monocyte-macrophage responses in vitro, in resolving skin blisters in vivo, and after cardiopulmonary bypass surgery. Circ. Res. 94, 119-126 (2004).

15. Polfliet, M.M., Fabriek, B.O., Daniels, W.P., Dijkstra, C.D. \& van den Berg, T.K. The rat macrophage scavenger receptor CD163: expression, regulation and role in inflammatory mediator production. Immunobiology 211, 419-425 (2006).

16. Sindrilaru, A. et al. An unrestrained proinflammatory M1 macrophage population induced by iron impairs wound healing in humans and mice. J. Clin. Invest. 121, 985-997 (2011).

17. Kelada, S.N. et al. Strain-dependent genomic factors affect allergeninduced airway hyper-responsiveness in mice. Am. J. Respir. Cell Mol. Biol. 45, 817-824 (2011).

18. Pope, S.M., Zimmermann, N., Stringer, K.F., Karow, M.L. \& Rothenberg, M.E. The eotaxin chemokines and CCR3 are fundamental regulators of allergen-induced pulmonary eosinophilia. J. Immunol. 175, 5341-5350 (2005).

19. Chapman, M.D. \& Platts-Mills, T.A. Purification and characterization of the major allergen from Dermatophagoides pteronyssinus-antigen P1. J. Immunol. 125, 587-592 (1980).

20. Madsen, M. et al. Molecular characterization of the haptoglobin.hemoglobin receptor CD163. Ligand binding properties of the scavenger receptor cysteine-rich domain region. J. Biol. Chem. 279, 51561-51567 (2004).

21. Kurowska-Stolarska, M. et al. IL-33 amplifies the polarization of alternatively activated macrophages that contribute to airway inflammation. J. Immunol. 183, 6469-6477 (2009).

22. Ochkur, S.I. et al. Coexpression of IL-5 and eotaxin-2 in mice creates an eosinophil-dependent model of respiratory inflammation with characteristics of severe asthma. J. Immunol. 178, 7879-7889 (2007).

23. Yang, M. et al. Eotaxin-2 and IL-5 cooperate in the lung to regulate IL-13 production and airway eosinophilia and hyperreactivity. J. Allergy Clin. Immunol. 112, 935-943 (2003).

24. Pope, S.M. et al. IL-13 induces eosinophil recruitment into the lung by an IL-5- and eotaxin-dependent mechanism. J. Allergy Clin. Immunol. 108, 594-601 (2001).

25. Campbell, H.D. et al. Molecular cloning, nucleotide sequence, and expression of the gene encoding human eosinophil differentiation factor (interleukin 5). Proc. Natl. Acad. Sci. USA 84, 6629-6633 (1987).

26. Stirling, R.G., van Rensen, E.L., Barnes, P.J. \& Chung, K.F. Interleukin-5 induces CD34(+) eosinophil progenitor mobilization and eosinophil CCR3 expression in asthma. Am. J. Respir. Crit. Care Med. 164 (8 Pt 1), 1403-1409 (2001).

27. Ponath, P.D. et al. Cloning of the human eosinophil chemoattractant, eotaxin. Expression, receptor binding, and functional properties suggest a mechanism for the selective recruitment of eosinophils. J. Clin. Invest. 97, 604-612 (1996)

28. Patel, V.P. et al. Molecular and functional characterization of two novel human C-C chemokines as inhibitors of two distinct classes of myeloid progenitors. J. Exp. Med. 185, 1163-1172 (1997).

29. Pope, S.M. et al. Identification of a cooperative mechanism involving interleukin-13 and eotaxin-2 in experimental allergic lung inflammation. J. Biol. Chem. 280, 13952-13961 (2005).

30. Staples, K.J., Hinks, T.S., Ward, J.A., Gunn, V., Smith, C. \& Djukanovic, R. Phenotypic characterization of lung macrophages in asthmatic patients: overexpression of CCL17. J. Allergy Clin. Immunol. 130, 1404-1412 (2012).

31. Sears, M.R. et al. A longitudinal, population-based, cohort study of childhood asthma followed to adulthood. N. Engl. J. Med. 349, 1414-1422 (2003).

32. Thomas, W.R., Hales, B.J. \& Smith, W.A. House dust mite allergens in asthma and allergy. Trends Mol. Med. 16, 321-328 (2010).

33. Nieuwenhuizen, N.E. et al. Allergic airway disease is unaffected by the absence of IL-4Ralpha-dependent alternatively activated macrophages. J. Allergy Clin. Immunol. 130, 743-750 (2012). 
34. Gregory, L.G. \& Lloyd, C.M. Orchestrating house dust mite-associated allergy in the lung. Trends Immunol. 32, 402-411 (2011).

35. Thomas, W.R., Smith, W.A., Hales, B.J., Mills, K.L. \& O'Brien, R.M. Characterization and immunobiology of house dust mite allergens. Int. Arch. Allergy Immunol. 129, 1-18 (2002).

36. Shakib, F., Schulz, O. \& Sewell, H. A mite subversive: cleavage of CD23 and CD25 by Der $\mathrm{p} 1$ enhances allergenicity. Immunol. Today 19, 313-316 (1998).

37. Deslee, G. et al. Involvement of the mannose receptor in the uptake of Der $p$ 1, a major mite allergen, by human dendritic cells. J. Allergy Clin. Immunol. 110, 763-770 (2002).

38. Comoy, E.E. et al. The house dust mite allergen, Dermatophagoides pteronyssinus, promotes type 2 responses by modulating the balance between IL-4 and IFN-gamma. J. Immunol. 160, 2456-2462 (1998).

39. Hewitt, C.R., Brown, A.P., Hart, B.J. \& Pritchard, D.I. A major house dust mite allergen disrupts the immunoglobulin Enetwork by selectively cleaving CD23: innate protection by antiproteases. J. Exp. Med. 182, 1537-1544 (1995).

40. Schulz, O., Sewell, H.F. \& Shakib, F. Proteolytic cleavage of CD25, the alpha subunit of the human T cell interleukin 2 receptor, by Der $p$ 1, a major mite allergen with cysteine protease activity. J. Exp. Med. 187, 271-275 (1998).

41. Ghaemmaghami, A.M., Gough, L., Sewell, H.F. \& Shakib, F. The proteolytic activity of the major dust mite allergen Der $\mathrm{p} 1$ conditions dendritic cells to produce less interleukin-12: allergen-induced Th2 bias determined at the dendritic cell level. Clin. Exp. Allergy 32, 1468-1475 (2002).

42. Furmonaviciene, R. et al. The protease allergen Der $p 1$ cleaves cell surface DC-SIGN and DC-SIGNR: experimental analysis of in silico substrate identification and implications in allergic responses. Clin. Exp. Allergy 37, 231-242 (2007).

43. Wan, H. et al. Der $\mathrm{p} 1$ facilitates transepithelial allergen delivery by disruption of tight junctions. J. Clin. Invest. 104, 123-133 (1999).

44. Kauffman, H.F., Tamm, M., Timmerman, J.A. \& Borger, P. House dust mite major allergens Der $p 1$ and Der $p 5$ activate human airway-derived epithelial cells by protease-dependent and protease-independent mechanisms. Clin. Mol. Allergy 4, 5 (2006).

45. Adam, E. et al. The house dust mite allergen Der p 1, unlike Der p 3, stimulates the expression of interleukin-8 in human airway epithelial cells via a proteinase-activated receptor-2-independent mechanism. J. Biol. Chem. 281, 6910-6923 (2006).

46. Ren, X. etal. FOXM1 promotes allergen-induced goblet cell metaplasia and pulmonary inflammation. Mol. Cell. Biol. 33, 371-386 (2013).

47. Papadopoulos, N.G. et al. Rhinovirus infection up-regulates eotaxin and eotaxin-2 expression in bronchial epithelial cells. Clin. Exp. Allergy 31, 1060-1066 (2001).

48. Valenzuela, D.M. et al. High-throughput engineering of the mouse genome coupled with high-resolution expression analysis. Nat. Biotechnol. 21, 652-659 (2003).

49. Yao, X. et al. Peptidoglycan recognition protein 1 promotes house dust mite-induced airway inflammation in mice. Am. J. Respir. Cell Mol. Biol. 49, 902-911 (2013).

50. Van Itallie, C.M., Tietgens, A.J., Logrande, K., Aponte, A., Gucek, M. \& Anderson, J.M. Phosphorylation of claudin-2 on serine 208 promotes membrane retention and reduces trafficking to lysosomes. J. Cell Sci. 125, 4902-4912 (2012). 